\title{
Measurements of the high frequency dynamic stiffness of railway ballast and subgrade
}

Xianying Zhang ${ }^{1 *}$, David Thompson ${ }^{1}$, Hongseok Jeong ${ }^{1}$, Martin Toward ${ }^{1}$, David Herron ${ }^{2}$, Chris Jones ${ }^{3}$, Nicolas Vincent ${ }^{4}$

1: Institute of Sound and Vibration Research, University of Southampton, Southampton SO17 1BJ, UK

2: Pandrol Rail Fastenings Ltd, Addlestone, Surrey, UK.

3: 78 Cliffe Road, Glossop, Derbyshire SK13 8NT, UK.

4: Vibratec, 28 Chemin du Petit Bois, Ecully Cedex 69131, France.

*: corresponding author. Email: xianyingzhang96@gmail.com

\begin{abstract}
Conventional railway tracks are laid in a layer of crushed stone known as ballast which contributes to the resilience of the track support. Beneath it is the subgrade which also has a considerable influence on the track support stiffness. Although quasi-static measurements of track stiffness are reasonably common, the dynamic stiffness at higher frequencies is required for noise and vibration modelling. Here, a distinction is made between the dynamic stiffness of the ballast layer itself and the dynamic support stiffness which includes the underlying ground. The dynamic transfer stiffness of a ballast layer is required for ground vibration and bridge noise predictions. Two different methods for measuring this are presented, one in the laboratory and the other in the field. The laboratory method is limited to a maximum frequency of about $600 \mathrm{~Hz}$ due to limitations of the test rig. The field measurement, which relies on identifying the wavespeed within the medium, gives results up to $2 \mathrm{kHz}$. These methods give broadly consistent results, with a stiffness per rail seat for a $300 \mathrm{~mm}$ thick ballast layer of approximately $300-500 \mathrm{MN} / \mathrm{m}$, increasing in proportion to the square root of the preload, and a damping loss factor in the range 0.15-0.3. The corresponding Young's modulus is between 200 and $700 \mathrm{MPa}$, depending on the preload. The dynamic stiffness increases above about $300 \mathrm{~Hz}$ with a first peak due to standing wave effects occurring at about $700 \mathrm{~Hz}$. The dynamic support stiffness beneath the sleeper, on the other hand, is required for rolling noise modelling. This has been measured using two methods: a direct
\end{abstract}


method for frequencies $50-500 \mathrm{~Hz}$ and an indirect method based on a modal analysis of a sleeper embedded in the ballast. A clear shift in natural frequencies is seen which is associated with the support stiffness. This support stiffness is strongly frequency-dependent, with the value per rail seat increasing from about $100-200 \mathrm{MN} / \mathrm{m}$ at $100 \mathrm{~Hz}$ to $2000 \mathrm{MN} / \mathrm{m}$ at $1 \mathrm{kHz}$. The support damping corresponds to a loss factor of around 1 for frequencies above $200 \mathrm{~Hz}$, or a damping coefficient of $100-200 \mathrm{kNs} / \mathrm{m}$ per rail seat. This damping is due to the radiation of energy into the ground rather than internal losses in the ballast. It strongly affects the modal damping of the sleeper and thus its radiated noise. The dynamic support stiffness increases roughly in proportion to the cube root of the preload. Comparison with a finite element model indicates that the underlying ground is responsible for the support stiffness and damping at low frequencies. However, above about $500 \mathrm{~Hz}$ it is independent of the ground and is only affected by the ballast layer. The results from the finite element model imply behaviour similar to a viscous damper. The sleeper vibration obtained using either a viscous damping or a constant loss factor is similar.

Keywords: railway ballast, dynamic stiffness, rolling noise, ground vibration, damping models

\section{Introduction}

Although concrete slab tracks have become popular in recent years, most railway tracks are still constructed with concrete or timber sleepers laid in a layer of crushed stone known as ballast [1]. This serves a number of functions, including spreading the loads from the train into the subgrade, providing lateral restraint, allowing drainage, enabling relatively simple correction of the vertical and lateral track geometry, and providing some vertical resilience in the track bed.

The track stiffness is an important parameter in quantifying the quality and performance of the track bed [2]. A lower track stiffness results in a wider 'deflection bowl' beneath each wheel; this spreads the load and reduces the stresses throughout the track structure; however, this is at the expense of increased rail bending. The track stiffness can be measured using a variety of methods [2,3], during train passages [4] or statically, e.g. using a falling weight deflectometer [5]. In addition to stiffness, the ballast and subgrade introduce damping to the 
track but in comparison with the stiffness, much less information is available about the damping properties of the track support.

There are various quantities used to describe the track stiffness [2]: the global track stiffness (force applied to the rail to cause a unit deflection, N/m), the support modulus (stiffness per unit length beneath the rail, $\left.\mathrm{N} / \mathrm{m}^{2}\right)$, and the support stiffness of an individual sleeper $(\mathrm{N} / \mathrm{m})$. These can each be expressed per rail (or railseat) or for the whole track (two rails). If they are measured at the rail they will include the resilience of the rail pads whereas a measurement at the sleepers excludes this. The support stiffness beneath the sleepers can also be expressed as a bedding modulus $\left(\mathrm{N} / \mathrm{m}^{3}\right)$ by dividing by the sleeper base area. Moreover, stiffness values may be obtained from the nonlinear load-deflection curve in different ways depending on the intended use. The secant stiffness is derived from the total range of deflection to an applied load and is used in studying track deflections under train loading; it may be influenced by voids beneath the sleepers, which will tend to reduce the apparent stiffness. The tangent stiffness, on the other hand, is derived from the slope of the load-deflection curve at a given preload, and is more appropriate for noise and vibration analysis where the response to small amplitude dynamic loading at higher frequencies is of interest.

Table 1 gives a summary of measured results from different sources, which for consistency have been converted into stiffness per railseat. Priest \& Powrie [6] and Le Pen et al. [4] derived the track stiffness by fitting a beam-on-elastic-foundation model to the track deflections under a passing train. Berggren et al. [7] used a modified track recording car to determine track deflection and stiffness. Kohler [8] studied the track stiffness at a number of sites on Swiss narrow gauge lines using measurements of track deflection during train passages and found a wide range of values, expressed as bedding modulus, of 0.01 to 0.39 $\mathrm{N} / \mathrm{mm}^{3}$. These results can be compared with guidelines given in $[9,10]$ which indicate that a bedding modulus of $0.02-0.05 \mathrm{~N} / \mathrm{mm}^{3}$ corresponds to poor support, $0.1-0.15 \mathrm{~N} / \mathrm{mm}^{3}$ to good support and $0.3-0.6 \mathrm{~N} / \mathrm{mm}^{3}$ to very stiff support. These can be converted to sleeper support stiffness for a nominal sleeper bearing area of $0.32 \mathrm{~m}^{2}$ (per rail seat) as listed in Table 1.

Models of high frequency track dynamics are used for rolling noise, ground vibration and corrugation modelling [11]. These contain elements representing the support stiffness and damping, although they are usually referred to as corresponding to the ballast. Knothe \& 
Grassie [11] summarised measured values of stiffness and damping of 'ballast' and rail pads from the literature [12-16]. The values for the support stiffness are listed in Table 1 along with other more recent results [17-19]. These are all expressed as the stiffness (or damping) per railseat. Most were obtained by fitting measured track receptances with a simple model. De France [17] measured the receptance of each sleeper of a section of track after disconnecting them from the rail and obtained the stiffness from the receptance in the frequency region 50-100 Hz. Comparing the various sources, quite a large range of values are seen. As indicated in the results of Grassie et al. [12], the stiffness is generally lower directly after tamping, increasing with time as the track is used.

Table 1 also lists results for the stiffness of the ballast itself obtained by fitting a suitable track model. Oscarsson [20] reports field measurements of ballast stiffness carried out at two sites in Sweden. The rail clips were disconnected and after applying a preload to close any gap below the sleeper, a dynamic excitation at $2 \mathrm{~Hz}$ was applied. The ballast stiffness was derived by assuming a subgrade stiffness of $600 \mathrm{MN} / \mathrm{m}$ which was subtracted from the measured stiffness assuming that it acts in series with the ballast stiffness. The mean and standard deviation over 20 sleepers were determined for each site. Igeland and Oscarsson [21] found much higher values for the ballast stiffness. Germonpré et al. [22] presented results measured using the IMV100 vehicle in Sweden. After fitting a model to the measured receptances, separate values for the ballast stiffness and damping were obtained, as listed in Table 1.

Table 1. Summary of experimental values obtained for low frequency support stiffness \& damping expressed per railseat.

\begin{tabular}{|l|l|l|l|l|l|}
\hline Author & $\begin{array}{l}\text { Stiffness MN/m } \\
(\sigma=\text { standard } \\
\text { deviation })\end{array}$ & $\begin{array}{l}\text { Damping } \\
\mathrm{kNs} / \mathrm{m} \\
(\text { or loss } \\
\text { factor } \eta)\end{array}$ & $\begin{array}{l}\text { Secant / } \\
\text { tangent }\end{array}$ & Loaded? & \\
\hline $\begin{array}{l}\text { Priest \& } \\
\text { Powrie [6] }\end{array}$ & $70-170$ & - & Secant & Yes & $\begin{array}{l}\text { Derived from track } \\
\text { deflections under trains }\end{array}$ \\
\hline $\begin{array}{l}\text { Le Pen et } \\
\text { al. [4] }\end{array}$ & $10-46$ & - & Secant & Yes & $\begin{array}{l}\text { Derived from track } \\
\text { deflections under trains. }\end{array}$ \\
\hline
\end{tabular}




\begin{tabular}{|c|c|c|c|c|c|}
\hline $\begin{array}{l}\text { Berggren } \\
\text { et al. [7] }\end{array}$ & $20-40$ & - & Secant & Yes & Special measurement car. \\
\hline Kohler [8] & $\begin{array}{l}6.5 \text { (very poor) } \\
16 \text { (poor) } \\
32-48 \text { (good) } \\
100-200 \text { (very } \\
\text { stiff) }\end{array}$ & - & Secant & Yes & $\begin{array}{l}\text { Derived from track } \\
\text { deflections under trains, } \\
\text { converted to stiffness per } \\
\text { sleeper end. Quoted from } \\
{[9,10]}\end{array}$ \\
\hline $\begin{array}{l}\text { Grassie et } \\
\text { al. [12] }\end{array}$ & $\begin{array}{l}180 \\
70\end{array}$ & $\begin{array}{l}82 \\
30\end{array}$ & Tangent & No & $\begin{array}{l}\text { Pre-tamping } \\
\text { Post-tamping } \\
\text { from [11] }\end{array}$ \\
\hline $\begin{array}{l}\text { Grassie \& } \\
\text { Cox [13] }\end{array}$ & 72 & 132 & Tangent & No & $\begin{array}{l}\text { Frozen ground, } \\
\text { from [11] }\end{array}$ \\
\hline $\begin{array}{l}\text { De France } \\
{[17]}\end{array}$ & $90(\sigma=31)$ & $\eta=1.0$ & Tangent & No & $\begin{array}{l}\text { Measured sleeper } \\
\text { receptance, } 50-100 \mathrm{~Hz}\end{array}$ \\
\hline $\begin{array}{l}\text { Vincent \& } \\
\text { Thompson } \\
{[18]}\end{array}$ & $\begin{array}{l}67 \\
70 \\
50 \\
50\end{array}$ & $\begin{array}{l}\eta=2.0 \\
\eta=1.0 \\
\eta=1.0 \\
\eta=1.0\end{array}$ & Tangent & No & $\begin{array}{l}\text { Model fitted to rail } \\
\text { receptance measurements } \\
\text { at four sites }\end{array}$ \\
\hline $\begin{array}{l}\text { Oregui et } \\
\text { al. [19] }\end{array}$ & 45 & 32 & Tangent & No & $\begin{array}{l}\text { From fitting to dynamic } \\
\text { track model }\end{array}$ \\
\hline Ripke [14] & 100 & 72 & Tangent & Yes & From [11] \\
\hline $\begin{array}{l}\text { Bancillon } \\
\text { et al. [15] }\end{array}$ & $\begin{array}{l}110 \\
180 \\
500\end{array}$ & - & Tangent & Yes & From [11] \\
\hline $\begin{array}{l}\text { Grassie \& } \\
\text { Cox [16] }\end{array}$ & 50 & 51 & Tangent & Yes & \\
\hline $\begin{array}{l}\text { Oscarsson } \\
{[20]}\end{array}$ & $\begin{array}{l}255(\sigma=16) \\
186(\sigma=22)\end{array}$ & - & Tangent & Yes & $\begin{array}{l}\text { Loaded ( } 85 \text { and } 125 \mathrm{kN} \text { ); } \\
\text { excited by special train, } \\
\text { large amplitude. Ballast } \\
\text { stiffness only }\end{array}$ \\
\hline $\begin{array}{l}\text { Igeland \& } \\
\text { Oscarsson } \\
{[21]}\end{array}$ & $\begin{array}{l}641 \\
767\end{array}$ & $\begin{array}{l}467 \\
460\end{array}$ & Tangent & Yes & $\begin{array}{l}\text { Wheel load } 90 \mathrm{kN} \\
\text { Wheel load } 130 \mathrm{kN} \\
\text { Ballast stiffness only }\end{array}$ \\
\hline
\end{tabular}




\begin{tabular}{|c|c|c|c|c|c|}
\hline $\begin{array}{l}\text { Germonpré } \\
\text { et al. [22] }\end{array}$ & 170 & 270 & Tangent & Yes & $\begin{array}{l}\text { Chosen to fit a more } \\
\text { complex model. Preload } \\
50 \mathrm{kN} \text { per rail. Ballast } \\
\text { stiffness only }\end{array}$ \\
\hline
\end{tabular}

Previous dynamic models for the track have included the ballast and subgrade in a number of ways [11]: as a Kelvin-Voigt element (spring and damper in parallel) [12, 23]; as a complex stiffness with a constant damping loss factor (the loss factor is equal to twice the damping ratio) [24, 25]; as a complex stiffness with consistent mass [26]. As reported by Zhai et al. [27], Ahlbeck et al. [28] assumed that the load distribution in the ballast follows a cone distribution with an angle corresponding to the Poisson's ratio; Zhai et al. [27] used a cone angle of $35^{\circ}$. They then developed a dynamic model incorporating an intermediate mass layer with a shear stiffness and damping connection between adjacent masses. They used a ballast stiffness of $140 \mathrm{MN} / \mathrm{m}$ and subgrade stiffness of $78 \mathrm{MN} / \mathrm{m}$ per railseat. Zakeri and Moshayebi [29] extended the cone model to three layers with varying cone angles but no comparison was given with field measurements.

Auersch [30] represented the ballast (as well as the soil) by a continuum with shear wave speed $270 \mathrm{~m} / \mathrm{s}$. He pointed out that the stiffness of ballasted track is strongly influenced by the stiffness of the soil, especially at low frequencies, and that a strong damping effect is caused by radiation into the soil. In [31] he used a range of shear wave speeds for the soil and ballast from $100 \mathrm{~m} / \mathrm{s}$ upwards. Hall [32] presented a finite element model of the track and soil and used a Young's modulus of 134.5 MPa for the ballast. In a similar approach Chebli et al. [33] used $209 \mathrm{MPa}$ for the Young's modulus of ballast. More recently the Discrete Element Modelling (DEM) method has been widely used to represent granular materials such as ballast, e.g. [34, 35]. Nevertheless, for the current application this is less suitable as the interest is in the behaviour at small amplitudes and high frequencies.

In reality, no resilient element is entirely massless; its mass leads to dynamic stiffening at higher frequencies due to the occurrence of internal resonances [36]. Moreover, if the mass of a resilient element can no longer be neglected, the point and transfer stiffnesses will not be equal. Thus a stiffness matrix should be defined; for example for a uniaxial resilient element this is given by: 


$$
\left\{\begin{array}{c}
F_{1} \\
-F_{2}
\end{array}\right\}=\left[\begin{array}{cc}
K_{11} & -K_{12} \\
-K_{21} & K_{22}
\end{array}\right]\left\{\begin{array}{l}
X_{1} \\
X_{2}
\end{array}\right\}
$$

where $F_{1}$ and $F_{2}$ are the forces acting at the two ends and $X_{1}$ and $X_{2}$ are the displacements of the two ends. The point stiffnesses, $K_{11}$ and $K_{22}$, are not necessarily equal but, by reciprocity, the transfer stiffnesses are, $K_{12}=K_{21}$. The dynamic transfer stiffness of the ballast layer is required for predictions of ground vibration and bridge noise, whereas the dynamic stiffness and damping of the foundation below the sleeper, i.e. the point support stiffness of the ballast and subgrade, is required for rolling noise modelling [37].

There are very few results in the literature on the frequency dependence of the ballast or track stiffness. Jones et al. [38] presented measurements of the stiffness of ballast which made use of force transducers mounted on a concrete block below the ballast. Herron et al. [39, 40] used a laboratory test method based on ISO 10846-3 [41] to measure the dynamic transfer stiffness of a ballast layer for frequencies up to $600 \mathrm{~Hz}$. Aikawa [42] developed a loadmeasuring concrete sleeper with a set of load sensors on its bottom surface. The acceleration on the sleeper surface and within the ballast layer were also measured under loading from passing trains. From this the Young's modulus of the ballast layer was derived as a function of frequency. It was found to increase with frequency, varying between 200 and $2000 \mathrm{MPa}$ between 100 and $1000 \mathrm{~Hz}$.

The aim of this paper is to present and compare several different methods of measuring the dynamic stiffness of ballast, with or without the subgrade. The dynamic transfer stiffness of a ballast layer has been measured using two different methods, one in the field [38] and the other in the laboratory [39]. These are described in Sections 2 and 3. The dynamic support stiffness beneath the sleeper has also been measured using two methods. Section 4 describes the use of a direct method for frequencies $50-500 \mathrm{~Hz}$. At higher frequencies the modal vibration response of a concrete sleeper is affected by the support stiffness and damping, allowing the stiffness and damping to be determined indirectly from a modal analysis; this is described in Section 5. In each of these measurements the amplitudes of vibration are sufficiently small that the low-strain stiffness is measured and strain dependence can be neglected. Comparisons are made with a finite element model of the ground in Section 6 to show the influence of the ballast and the subgrade on the dynamic support stiffness. Finally, in Section 7 the effects of various models of the support stiffness on the sleeper dynamic response are compared, which has implications for rolling noise modelling. 


\section{Young's modulus of ballast layer measured in situ}

\subsection{Method}

In this section measurements taken on a test track are presented from which the Young's modulus of the ballast can be derived. These measurements were previously described in [38] but are reanalysed here. A $36 \mathrm{~m}$ long test track with concrete sleepers was laid at the University of Southampton in 1997. Prior to its construction, a concrete slab of thickness 30 $\mathrm{cm}$ and approximate dimensions $3.0 \times 2.0 \mathrm{~m}$ was installed below the ballast. Five specially constructed force transducers were laid on the upper surface of the slab and covered in a thin layer of sand to protect them. The track was then constructed above this. The ballast had a nominal depth of $0.3 \mathrm{~m}$ beneath the sleeper soffits, and was then filled around the sleepers. The ballast was compacted with a vibro-tamper during construction.

For the measurements, one sleeper was disconnected from the rail. A static load was applied to one end of this sleeper via a soft insulation mount $(3 \mathrm{MN} / \mathrm{m})$ by using piles of bricks on a thick steel plate, see Figure 1. The load applied through the insulation mount to one end of the sleeper was varied from $3 \mathrm{kN}$ up to $35 \mathrm{kN}$ [38]. The weight of half the concrete sleeper $(1.5 \mathrm{kN})$ can also be considered to act on the ballast and is added to these preloads. The dynamic properties of the ballast were measured by exciting the sleeper with a small impact hammer and measuring the acceleration of the sleeper as well as the blocked force acting on the concrete slab.

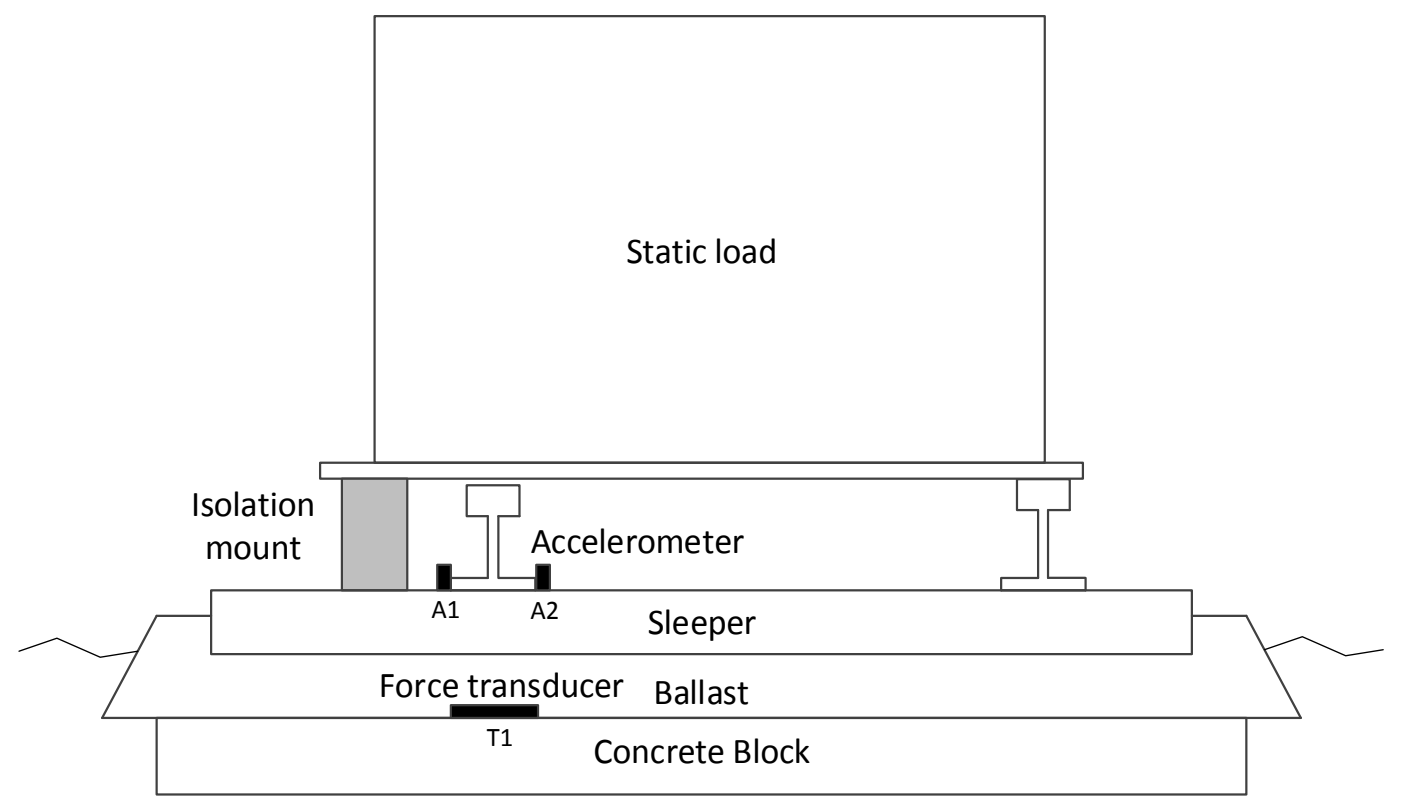


Figure 1. Experimental arrangement for in situ measurement of ballast Young's modulus.

\subsection{Results}

The transfer stiffness cannot easily be extracted from these results as the force is only sampled at certain points on the concrete slab. However, the phase of the transfer stiffness provides information about the wavespeed of compressional waves in the ballast. Figure 2 shows this unwrapped phase for several values of preload.

To interpret these results, the loaded ballast region can be represented as a column of elastic material. For a uniform rod, the transfer stiffness $K_{12}$ is given by [36]

$$
K_{12}=\frac{E k A_{1}}{\sin (k h)}
$$

where $E$ is the Young's modulus, $h$ is the depth of the rod and $A_{1}$ is its cross-sectional area. $k$ is the wavenumber in the rod, given by,

$$
k=\frac{\omega}{(E / \rho)^{1 / 2}}
$$

where $\omega$ is the circular frequency and $\rho$ is the density.

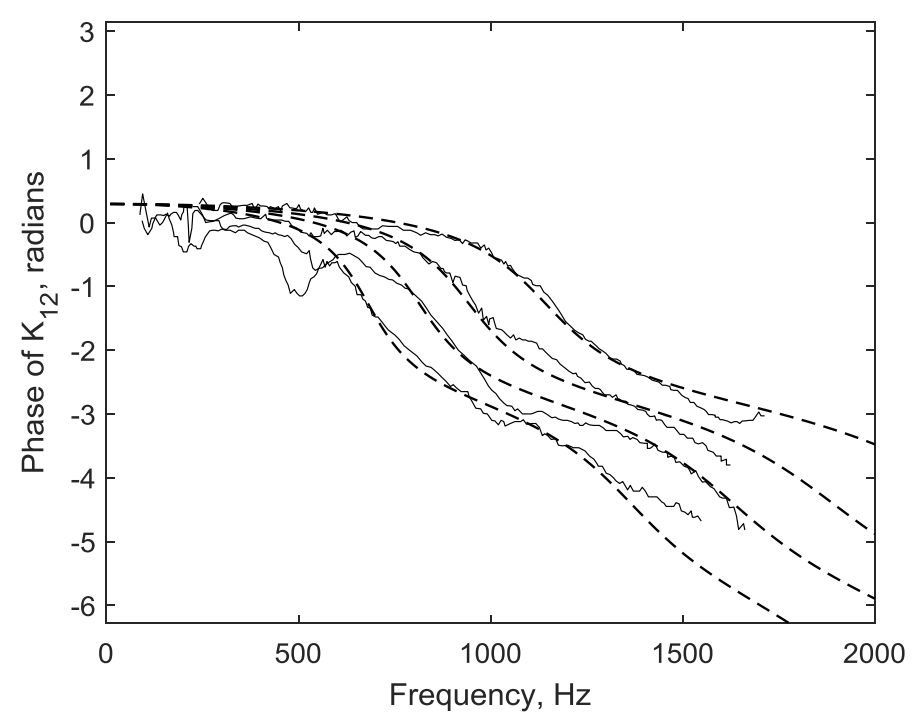

Figure 2. Measured phase of transfer function from sleeper displacement to blocked force (solid lines). Results from analytical model are shown as dashed lines. From bottom to top, preloads of 4.4, 10.6, 18.0 and $36.5 \mathrm{kN}$. 
For a tapered frustum, the load in the ballast is assumed to spread outwards in each direction at a certain angle. The transfer stiffness is given by,

$$
K_{12}=\frac{E k \sqrt{A_{1} A_{2}}}{\sin (k h)}
$$

where $A_{1}$ is the area of the upper face of the frustum and $A_{2}$ is the area of its lower face. Again in this case the wavenumber is given by Eq. (3). Results from either model are shown for comparison in Figure 2. A damping loss factor of 0.3 is used (equivalent to a damping ratio of 0.15 ) by making $E$ and $k$ complex. The corresponding values of equivalent Young's modulus are given in Table 2, assuming a density of $1500 \mathrm{~kg} / \mathrm{m}^{3}$. This modulus is plotted against preload $N$ in Figure 3, showing a dependence of $N^{1 / 2}$. In soil mechanics it is often found that the shear modulus of materials such as dry sand at very small strains depends on the effective confining pressure $p$ according to $p^{0.5}$, while at higher strains a larger exponent applies $[43,44]$. This behaviour is broadly consistent with a Hertzian contact model, the flexibility generally being due to the contacts between ballast stones. It should be noted that these results are sensitive to the value of $h$, the depth of the ballast layer, which was not known precisely. For example if the ballast layer was only $0.25 \mathrm{~m}$ deep below the sleepers, the values of $E$ would be only $70 \%$ of those listed in Table 2.

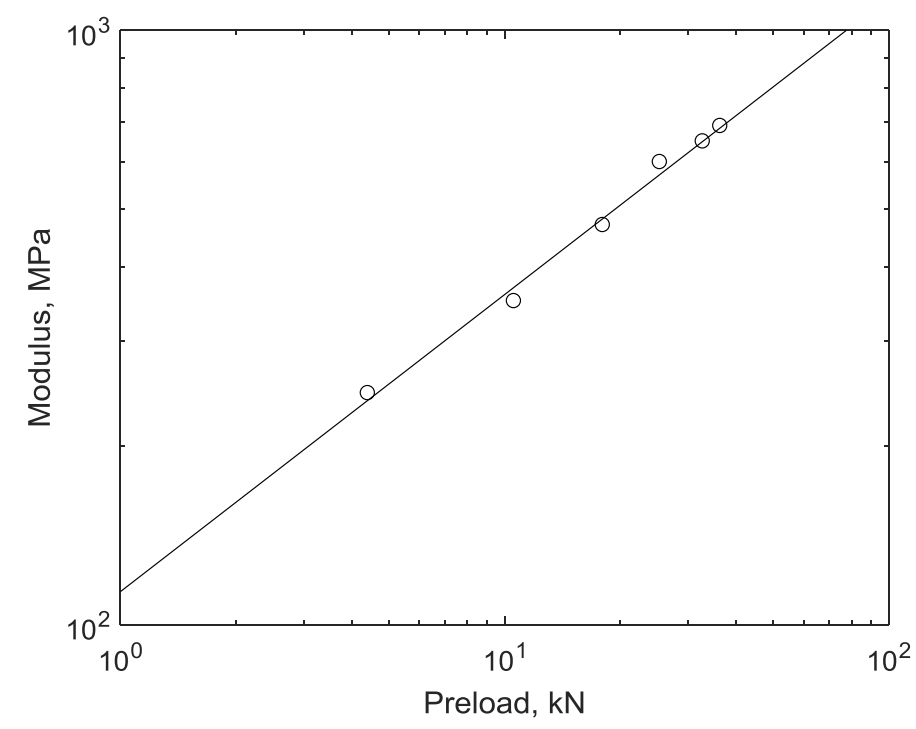

Figure 3. Equivalent Young's modulus obtained from phase of transfer stiffness in Figure 2. Fitted line corresponds to a slope of $N^{1 / 2}$.

Two estimates of the transfer stiffness are given in Table 2, which correspond to the low frequency asymptote of Eq. (2) for the rod and Eq. (4) for a frustum with angle $30^{\circ}$ on either 
side of the sleeper. The values of stiffness are broadly consistent with the results from [20-22] for the ballast layer, see Table 1.

Table 2. Summary of results from blocked force measurement (stiffness values assuming $A_{1}$ $\left.=0.325 \mathrm{~m}^{2}\right)$.

\begin{tabular}{|l|l|l|l|l|}
\hline Preload, kN & Wavespeed, m/s & $\begin{array}{l}\text { Equivalent } \\
\text { Young's } \\
\text { modulus, MPa }\end{array}$ & $\begin{array}{l}\text { Stiffness for rod } \\
\text { model, MN/m }\end{array}$ & $\begin{array}{l}\text { Stiffness for } \\
\text { frustum with } \\
30^{\circ}, \mathrm{MN} / \mathrm{m}\end{array}$ \\
\hline 4.4 & 404 & 245 & 265 & 405 \\
\hline 10.6 & 483 & 350 & 379 & 579 \\
\hline 18.0 & 560 & 470 & 509 & 778 \\
\hline 25.4 & 632 & 600 & 650 & 993 \\
\hline 32.8 & 658 & 650 & 704 & 1080 \\
\hline 36.5 & 678 & 690 & 748 & 1140 \\
\hline
\end{tabular}

\section{Laboratory measurement of the dynamic stiffness of a layer of ballast}

\subsection{Test rig}

This section describes laboratory measurements of the dynamic stiffness of a layer of ballast, previously described in $[39,40]$. These were carried out using the indirect method of ISO 10846-3 [41]. A dedicated test rig was constructed, shown schematically in Figure 4(a). The concrete base slab was $950 \mathrm{~mm}$ (length) $\times 630 \mathrm{~mm}$ (width) $\times 500 \mathrm{~mm}$ (height), with a mass of $850 \mathrm{~kg}$. It behaves as a rigid mass in the frequency region up to approximately $600 \mathrm{~Hz}$, with its first bending natural frequency occurring at around $1500 \mathrm{~Hz}$. This was supported on layers of resilient material along the edges. 


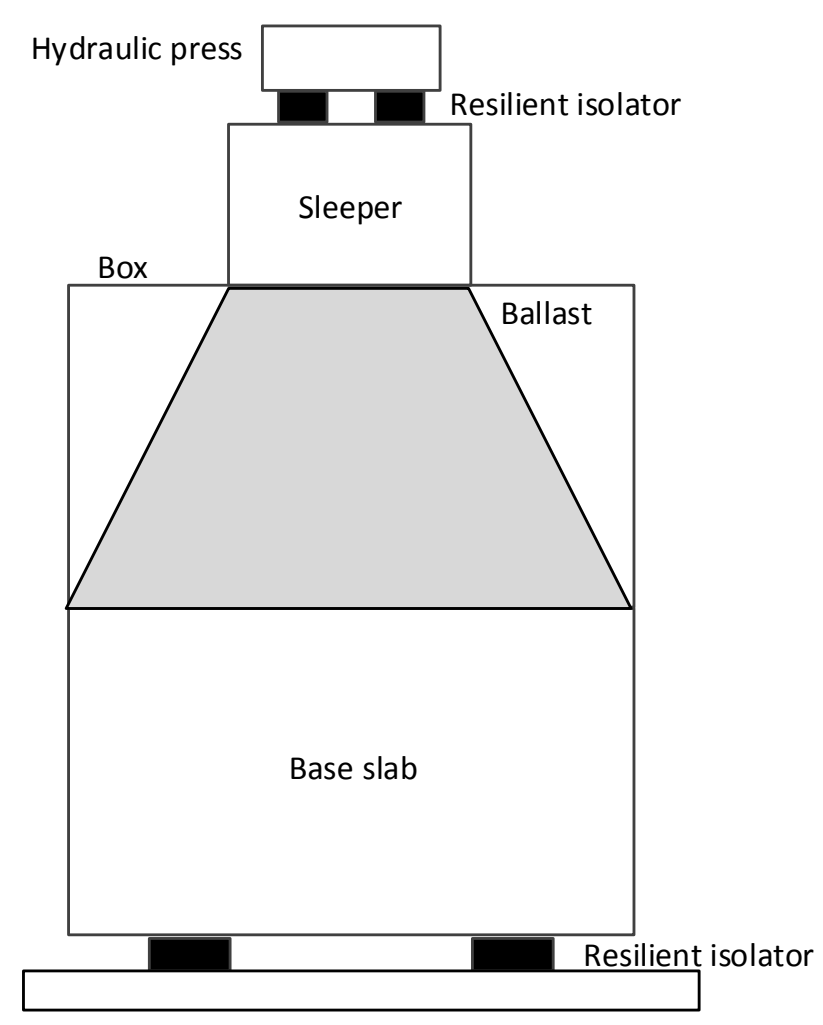

(a)

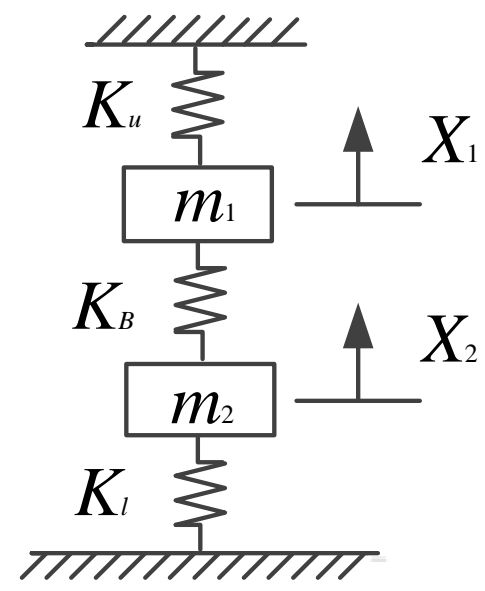

(b)

Figure 4. (a) Experimental set up; (b) equivalent two degree of freedom system.

Layers of ballast with a thickness of 300 and $450 \mathrm{~mm}$ were installed in a wooden box fitted on top of the base slab. A smaller concrete block of dimensions $600 \mathrm{~mm}$ (length) $\times 280 \mathrm{~mm}$ (width) $\times 300 \mathrm{~mm}($ depth) was used to represent part of a sleeper. A hydraulic preload was applied to this upper block through resilient isolators. The ballast layer was prepared for each test by applying a series of load cycles, with a maximum load of $100 \mathrm{kN}$. This was intended to reproduce the initial rapid settlement expected for the ballast in railway track.

Measurements were then made with a range of static preloads from $10 \mathrm{kN}$ to $100 \mathrm{kN}$. The sleeper block was excited dynamically using an impact hammer and the response of both upper and lower blocks was measured using accelerometers.

The test rig can be represented as a two-degree-of-freedom system, as shown in Figure 4(b). Here, $K_{u}$ is the combined stiffness of the upper isolators, required to isolate the upper mass from the actuator applying the preload, $K_{B}$ represents the ballast stiffness (actually a stiffness matrix, see Eq. (1)), which is to be measured, and $K_{l}$ corresponds to the combined stiffness of the isolators below the rig. $m_{1}$ and $m_{2}$ denote the masses of the 'sleeper' block and the base slab, while $X_{1}$ and $X_{2}$ are their vertical complex displacement amplitudes. 
The transfer stiffness of the ballast layer is obtained from the accelerations of the two masses:

$$
K_{12}=\frac{-\omega^{2} m_{2} X_{2}}{X_{1}-X_{2}}=-\omega^{2} m_{2}\left(\frac{\ddot{X}_{1}}{\ddot{X}_{2}}-1\right)
$$

Thus the measurement relies on obtaining the transfer function $\ddot{X}_{1} / \ddot{X}_{2}$ between the sleeper and the base slab accelerations. However, at very low frequencies the vibration of the sleeper and the base slab are almost equal so that this measurement becomes ill-conditioned. Moreover, at high frequencies the assumption that the masses are rigid breaks down. Valid measurements are obtained for frequencies between approximately 50 and $600 \mathrm{~Hz}$ with the current apparatus.

\subsection{Results}

Measurements were made for layers of new granite ballast with thicknesses of 300 and $450 \mathrm{~mm}$. For each configuration, the measurements were repeated for three 'seatings' of the sleeper. The sleeper was removed in each case, the ballast was then removed and repoured before reseating the sleeper. Examples of measured stiffness are shown in Figure 5. The results are close to a constant value at low frequencies but rise to a peak at $500 \mathrm{~Hz}$ for the 450 $\mathrm{mm}$ layer. For the $300 \mathrm{~mm}$ layer the low frequency stiffness is higher and the peak occurs beyond the measured frequency range. Comparison is also made with results from the frustum model, Equation (4). Reasonable agreement can be seen between them in terms of both the amplitude and the phase for the two thicknesses. The values used here are a Young's modulus of $214 \mathrm{MN} / \mathrm{m}^{2}$, density of $1500 \mathrm{~kg} / \mathrm{m}^{3}$ and angles of $20^{\circ}$ for the $300 \mathrm{~mm}$ case and $10^{\circ}$ for the $450 \mathrm{~mm}$ case; the damping loss factor is set to 0.3 . This value of Young's modulus is lower than the values found in Section 2 (see Table 2) but is consistent with the value used by Chebli et al. [33] and the low frequency value of Aikawa [42]. 

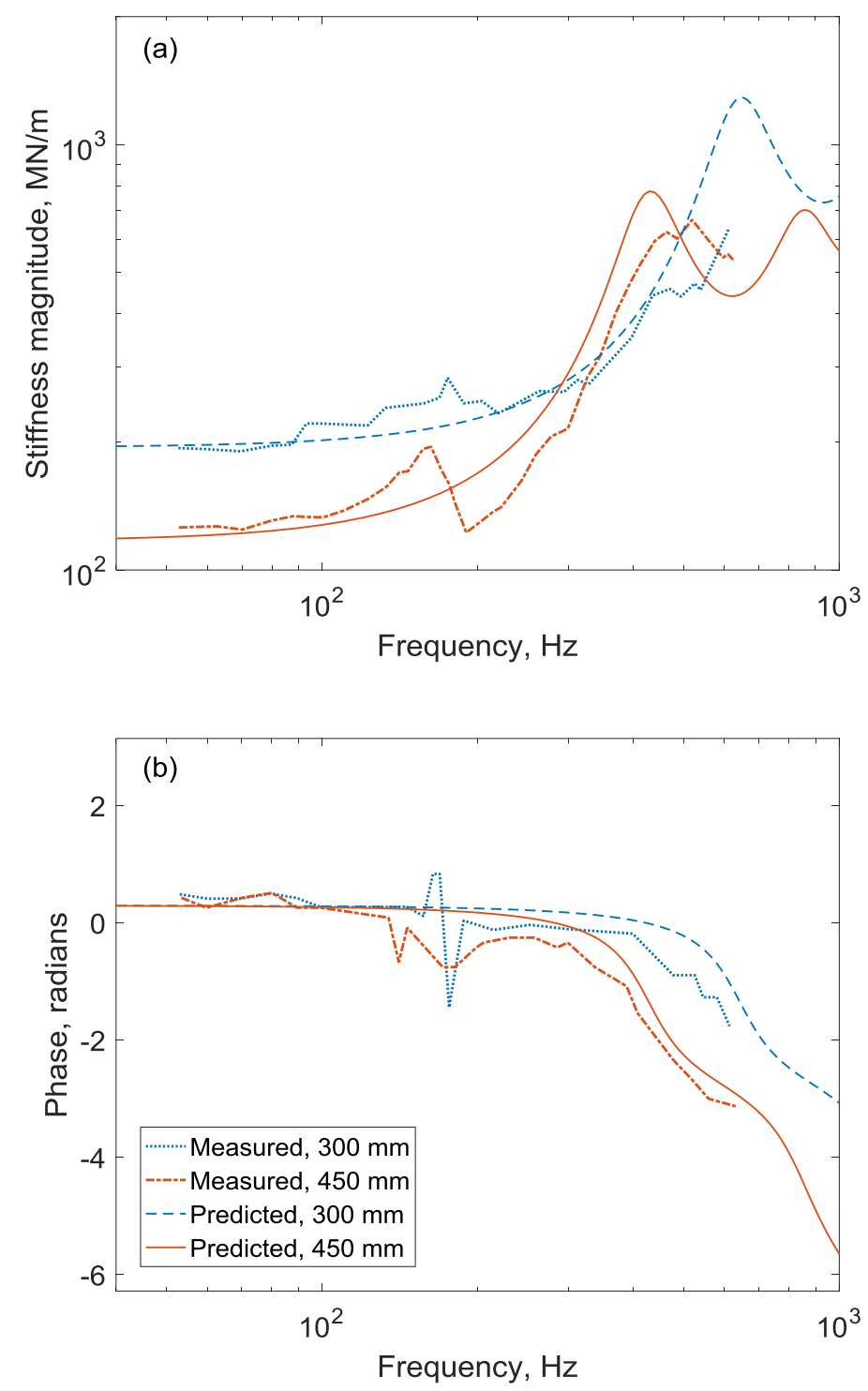

Figure 5. Magnitude (a) and phase (b) of the ballast transfer stiffness for a layer of ballast $300 \mathrm{~mm}$ and $450 \mathrm{~mm}$ thick subject to a preload of $20 \mathrm{kN}$. Contact area $0.168 \mathrm{~m}^{2}$.

The effect of preload on the stiffness and corresponding Young's modulus is summarised in Figure 6(a). These are results for a thickness of $300 \mathrm{~mm}$, and are extracted at $100 \mathrm{~Hz}$, where the stiffness is approximately independent of frequency. The average result and the range are shown for each preload, along with a line with a slope corresponding to $N^{1 / 2}$ where $N$ is the preload. This line gives a good fit to the load dependence for preloads up to $60 \mathrm{kN}$. A similar dependence was found in Figure 3. 

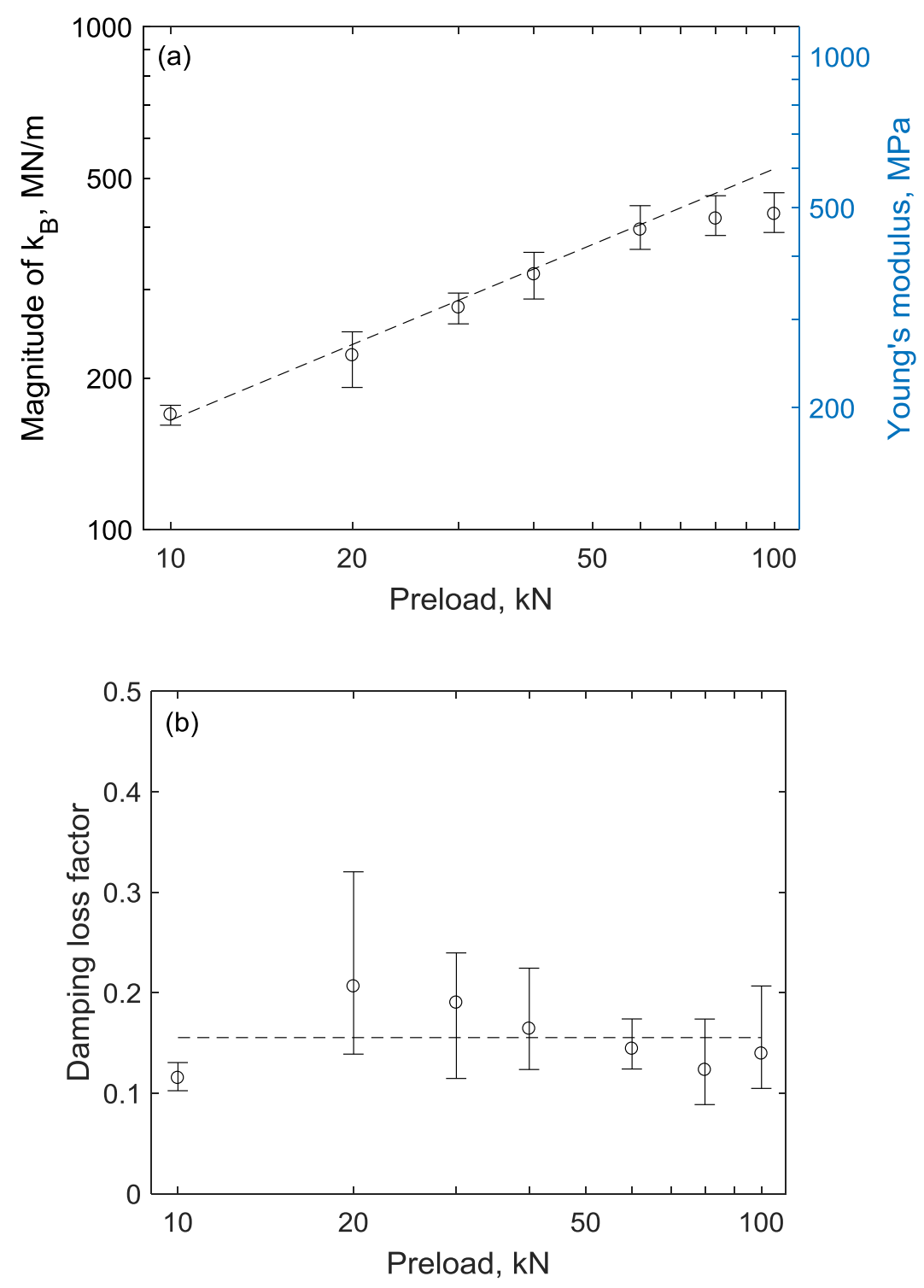

Figure 6. (a) Magnitude of the ballast transfer stiffness at $100 \mathrm{~Hz}$; (b) corresponding damping loss factor, for a $300 \mathrm{~mm}$-deep layer of ballast: o, mean; I, range. Contact area $0.168 \mathrm{~m}^{2}$.

The mean dynamic stiffness at $100 \mathrm{~Hz}$ obtained in these tests increases from $170 \mathrm{MN} / \mathrm{m}$ at 10 $\mathrm{kN}$ preload to $420 \mathrm{MN} / \mathrm{m}$ at $100 \mathrm{kN}$, corresponding to Young's moduli between 195 and 480 MPa. Although the stiffness values are smaller than those found in Section 2, they correspond to a smaller loading area $\left(0.168 \mathrm{~m}^{2}\right.$ compared with $\left.0.325 \mathrm{~m}^{2}\right)$. The corresponding damping loss factors, obtained from the phase angle of the dynamic stiffness at $100 \mathrm{~Hz}$, are shown in Figure 6(b). There is considerable variability in these results but the average loss factor is between 0.1 and 0.2 . 


\section{In situ measurements of direct support stiffness}

Measurements of support stiffness were taken at a test track in France using a direct method in which a dynamic load was applied to the ballast through a rigid structure and the force and response were measured on this structure [45]. The track consisted of bibloc sleepers and a layer of ballast $0.35 \mathrm{~m}$ thick below the sleepers. Two different loading structures were used; the first was a single block of a bibloc concrete sleeper and the second a stiffened aluminium plate.

On the test track, one length of rail about $15 \mathrm{~m}$ long was removed leaving the sleepers in place. A static preload was applied to the test sleeper through flexible rubber mounts; their dynamic stiffness was very low compared with that of the ballast and ground. The sleeper block was then excited by a large instrumented hammer, with mass $1.5 \mathrm{~kg}$, and its vibration was measured using accelerometers. Both the dynamic excitation force $F_{s}$ applied on the sleeper block and its average vibration response $X_{b}$ in the vertical direction were measured.

To obtain the complex dynamic stiffness of the ballast, mass compensation is applied. The complex ratio of the force $F_{b}$ applied to the ballast to its displacement amplitude $X_{b}$ is given by

$$
F_{b} / X_{b}(\omega)=F_{s} / X_{b}(\omega)+M \omega^{2}
$$

where $M$ is the mass, which for the sleeper block was $120 \mathrm{~kg}$. As can be seen, at high frequency, the term $M \omega^{2}$ will become larger than the stiffness of the ballast and subgrade $F_{b} / X_{b}(\omega)$. Any error in the measured transfer function will be amplified by the mass compensation. Therefore the measurement is limited to frequencies for which the mass impedance is smaller than that of the ballast, which in this case is $200 \mathrm{~Hz}$. Another potential limitation of this method is caused by elastic deformation of the structure. However, for the sleeper block this does not affect the results until above $1000 \mathrm{~Hz}$. At low frequency the measurement is limited by the signal-to-noise ratio; results are therefore only presented above $50 \mathrm{~Hz}$.

The results are summarised in Table 3. The measured dynamic stiffness magnitude of the ballast increases with increasing frequency. The phase increases strongly from $50 \mathrm{~Hz}$ to 100 $\mathrm{Hz}$, above which it tends to about $45^{\circ}$, corresponding to a damping loss factor close to 1 . 
When the static load was increased from $11 \mathrm{kN}$ to $21 \mathrm{kN}$, the stiffness increased by about $20 \%$. The damping loss factor, however, was not significantly affected by the static loading.

In addition to the concrete sleeper block, a stiffened aluminium loading plate with dimensions $0.25 \mathrm{~m} \times 0.3 \mathrm{~m}$ was constructed, with a mass of $5.1 \mathrm{~kg}$. The sleeper, used in the above measurement, was removed carefully in order not to disturb the ballast conditions and then replaced by the aluminium plate which was again loaded through two flexible mounts. It gave usable results up to $500 \mathrm{~Hz}$, above which deformation of the structure occurred. In this case, in addition to the large hammer used for the sleeper block, a smaller hammer of mass $0.3 \mathrm{~kg}$ with a stiffer tip was also used to cover the frequency range from 200 to $500 \mathrm{~Hz}$. To allow a direct comparison with the results from the sleeper block, both the stiffness and the preload are factored by the ratio of their surface areas. The sleeper block base area was $0.235 \mathrm{~m}^{2}$ whereas for the aluminium plate it was $0.075 \mathrm{~m}^{2}$, giving a ratio of 3.1 . These results are also summarised in Table 3. Again, the doubling of the static preload leads to an increase of about $20 \%$ in the dynamic stiffness whereas the damping loss factor did not vary significantly. The dynamic stiffness values obtained from the aluminium plate are higher than those from the sleeper block, but this is consistent with a higher equivalent preload. The results obtained with the two impact hammers are broadly consistent with one another.

Table 3. Support stiffness magnitude and phase from direct method (normalised to area of

$$
\left.0.235 \mathrm{~m}^{2}\right)
$$

\begin{tabular}{|l|l|c|c|c|c|c|c|}
\hline \multirow{2}{*}{$\begin{array}{l}\text { Loading } \\
\text { structure }\end{array}$} & \multirow{2}{*}{$\begin{array}{l}\text { Static load } \\
\text { for } 0.235 \\
\mathrm{~m}^{2}\end{array}$} & \multicolumn{2}{|c|}{$50 \mathrm{~Hz}$} & \multicolumn{2}{c|}{$200 \mathrm{~Hz}$} & \multicolumn{2}{c|}{$500 \mathrm{~Hz}$} \\
\cline { 2 - 8 } & $11 \mathrm{kN}$ & 130 & 17 & 220 & 49 & - & - \\
\cline { 2 - 8 } & $21 \mathrm{kN}$ & 148 & 14 & 280 & 54 & - & - \\
\hline Sleeper & $31 \mathrm{kN}$ & 210 & 27 & 270 & 65 & - & - \\
\hline $\begin{array}{l}\text { Aluminium } \\
\text { plate (large } \\
\text { hammer) }\end{array}$ & $62 \mathrm{kN}$ & 245 & 34 & 330 & 61 & - & - \\
\hline $\begin{array}{l}\text { Aluminium } \\
\text { plate (small } \\
\text { hammer) }\end{array}$ & $31 \mathrm{kN}$ & - & - & 300 & 45 & 630 & 45 \\
\cline { 2 - 8 } & $62 \mathrm{kN}$ & - & - & 360 & 30 & 700 & 47 \\
\hline
\end{tabular}




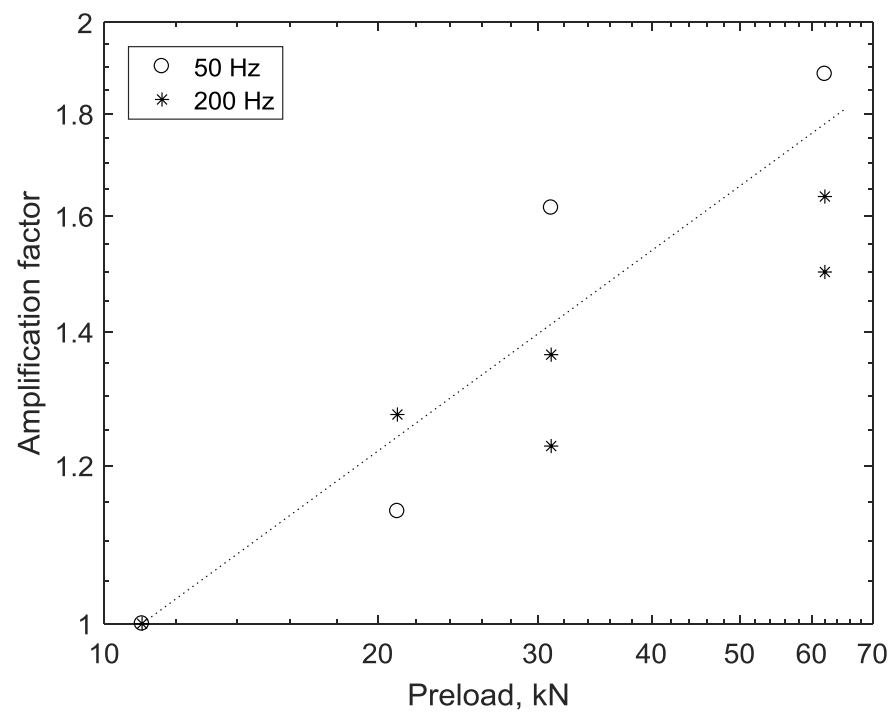

Figure 7. Effect of preload on dynamic support stiffness (normalised to loading area 0.235 $\mathrm{m}^{2}$ ). Dotted line represents $1 / 3$ power law.

The effect of preload on the dynamic stiffness is summarised in Figure 7, in which the results at each frequency are normalised to those at a preload of $11 \mathrm{kN}$. Although there is a large scatter, these results approximately follow a 1/3 power law, unlike the stiffness of the ballast layer itself in Sections 2 and 3 which follows a half power law. This difference is probably caused by the influence of the ground beneath the ballast layer in the current measurements. There is no obvious trend in the variation of damping loss factor with preload (Table 3).

\section{Indirect measurements of support stiffness based on sleeper bending modes}

\subsection{Measurements}

Measurements have also been carried out using an indirect approach to obtain support stiffness values at higher frequencies. This method consists in comparing modal analysis results for a concrete sleeper in 'free' and 'in situ' conditions. The stiffness and damping values for the support are then derived by fitting a finite element model to the results around the natural frequencies of the sleeper.

The first set of measurements was made on an operational track near Bern in Switzerland [45]. The track consisted of monobloc concrete sleepers of type B70-W. The sleeper mass was $280 \mathrm{~kg}$ with a contact area of $0.65 \mathrm{~m}^{2}$ with the ballast. For the in situ tests, the rails were 
disconnected from the sleeper and the rail pads were removed in order to prevent any contact between the rail and the sleeper. No additional preload was applied. For the free configuration, the sleeper was laid on two very flexible rubber mounts. For both tests, the sleeper was excited by an instrumented hammer in the vertical direction at one end and the acceleration was measured at 30 points on the surface of the sleeper in the vertical direction, 15 along each edge.

A finite element model of the sleeper was established and the material properties were adjusted to give a good match to the natural frequencies of the free sleeper. This gave a density of $2570 \mathrm{~kg} / \mathrm{m}^{3}$, Young's modulus of $43 \mathrm{GPa}$ and Poisson's ratio of 0.16 . The first seven natural frequencies were obtained to within $1 \%$ of the measured value and the eighth mode to within $2 \%$. The 'in situ' sleeper was then represented by the same finite element model, connected to the ground by a layer of damped springs. First, the stiffness of this layer was adjusted so that the changes in calculated natural frequencies matched the experimental ones. The damping was then selected in order to obtain the same modal damping in the calculated frequency response as in the measured one. This procedure was carried out for each bending mode of the sleeper. The equivalent ballast stiffness (real part) and damping loss factor were finally extracted from this model as a function of frequency. The results are listed in Table 4. Additional measurements were carried out under a preload of $40 \mathrm{kN}$. However, it was found that individual modes of the sleeper could no longer be identified, rendering the method unusable in this case.

A second measurement was made on the test track in Southampton [37]. The concrete sleeper was measured first in the laboratory before being installed in the test track. Unlike the first track, no traffic has passed the site. The natural frequencies and modal damping loss factors of the sleeper measured in these two conditions are listed in Table 5. The corresponding support stiffnesses (real part) and damping loss factors are also listed. The stiffness values are similar to those in Table 4 although the damping loss factors are smaller. 
Table 4. Measurement results obtained for sleeper 1 in situ without static load.

\begin{tabular}{|c|c|c|c|c|c|}
\hline \multicolumn{2}{|c|}{ In free condition } & \multicolumn{2}{c|}{ In situ } & \multicolumn{2}{c|}{ Support properties } \\
\hline $\begin{array}{c}\text { Natural } \\
\text { frequency, Hz }\end{array}$ & $\begin{array}{c}\text { Damping } \\
\text { loss factor }\end{array}$ & $\begin{array}{c}\text { Natural } \\
\text { frequency, } \\
\mathrm{Hz}\end{array}$ & $\begin{array}{c}\text { Damping } \\
\text { loss factor }\end{array}$ & $\begin{array}{c}\text { Stiffness, } \\
\text { MN/m } \\
\text { contact area } \\
\left.0.65 \mathrm{~m}^{2}\right)\end{array}$ & $\begin{array}{c}\text { Damping loss } \\
\text { factor }\end{array}$ \\
\hline 112 & 0.009 & 152 & 0.44 & 120 & 0.6 \\
\hline 340 & 0.01 & 416 & 0.46 & 900 & 1.0 \\
\hline 652 & 0.01 & 720 & 0.25 & 1200 & 1.15 \\
\hline 1026 & 0.01 & 1104 & 0.18 & 2250 & 1.12 \\
\hline 1450 & 0.008 & 1556 & 0.15 & 4000 & 0.96 \\
\hline 1909 & 0.009 & 2000 & 0.11 & 4500 & 1.05 \\
\hline 2389 & 0.008 & 2472 & 0.09 & 5300 & 1.15 \\
\hline 2891 & 0.008 & 2992 & 0.09 & 7300 & 1.14 \\
\hline
\end{tabular}

Table 5. Measurement results obtained for sleeper 2 in situ without static load.

\begin{tabular}{|c|c|c|c|c|c|}
\hline \multicolumn{2}{|c|}{ In free condition } & \multicolumn{2}{c|}{ In situ } & \multicolumn{2}{c|}{ Support properties } \\
\hline $\begin{array}{c}\text { Natural } \\
\text { frequency, Hz }\end{array}$ & $\begin{array}{c}\text { Damping } \\
\text { loss factor }\end{array}$ & $\begin{array}{c}\text { Natural } \\
\text { frequency, } \mathrm{Hz}\end{array}$ & $\begin{array}{c}\text { Damping } \\
\text { loss factor }\end{array}$ & $\begin{array}{c}\text { Stiffness, MN/m } \\
\text { contact area } \\
\left.0.67 \mathrm{~m}^{2}\right)\end{array}$ & $\begin{array}{c}\text { Damping } \\
\text { loss factor }\end{array}$ \\
\hline 120 & 0.008 & 186 & 0.815 & 369 & 0.48 \\
\hline 352 & 0.010 & 428 & 0.350 & 910 & 0.73 \\
\hline 682 & 0.013 & 745 & 0.143 & 1140 & 0.76 \\
\hline 1036 & 0.015 & 1136 & 0.094 & 3100 & 0.40 \\
\hline 1483 & 0.011 & 1616 & 0.068 & 5630 & 0.32 \\
\hline 1943 & 0.020 & 2077 & 0.047 & 7070 & 0.20 \\
\hline
\end{tabular}

\subsection{Discussion}

These results are compared in Figure 8 with those from the direct method, listed in Table 3. In both cases the results are shown for one rail seat. Thus the results for the monobloc sleeper are normalised to half the base area of the sleeper, i.e. $0.325 \mathrm{~m}^{2}$, whereas the results from the previous section are normalised to the area of one block of the bibloc sleeper, $0.235 \mathrm{~m}^{2}$.

Despite these differences, the results can be considered to be equivalent as, in practice, the 
contact area beneath a monobloc sleeper is actually concentrated in the rail seat region. These results show that the stiffness increases approximately in proportion to frequency whereas the damping loss factor is roughly independent of frequency. The results from the direct and indirect methods are broadly consistent. The stiffness value at $152 \mathrm{~Hz}$ for sleeper 1 may be artificially low as the first bending mode and the bounce mode of the sleeper on the ballast are difficult to distinguish.
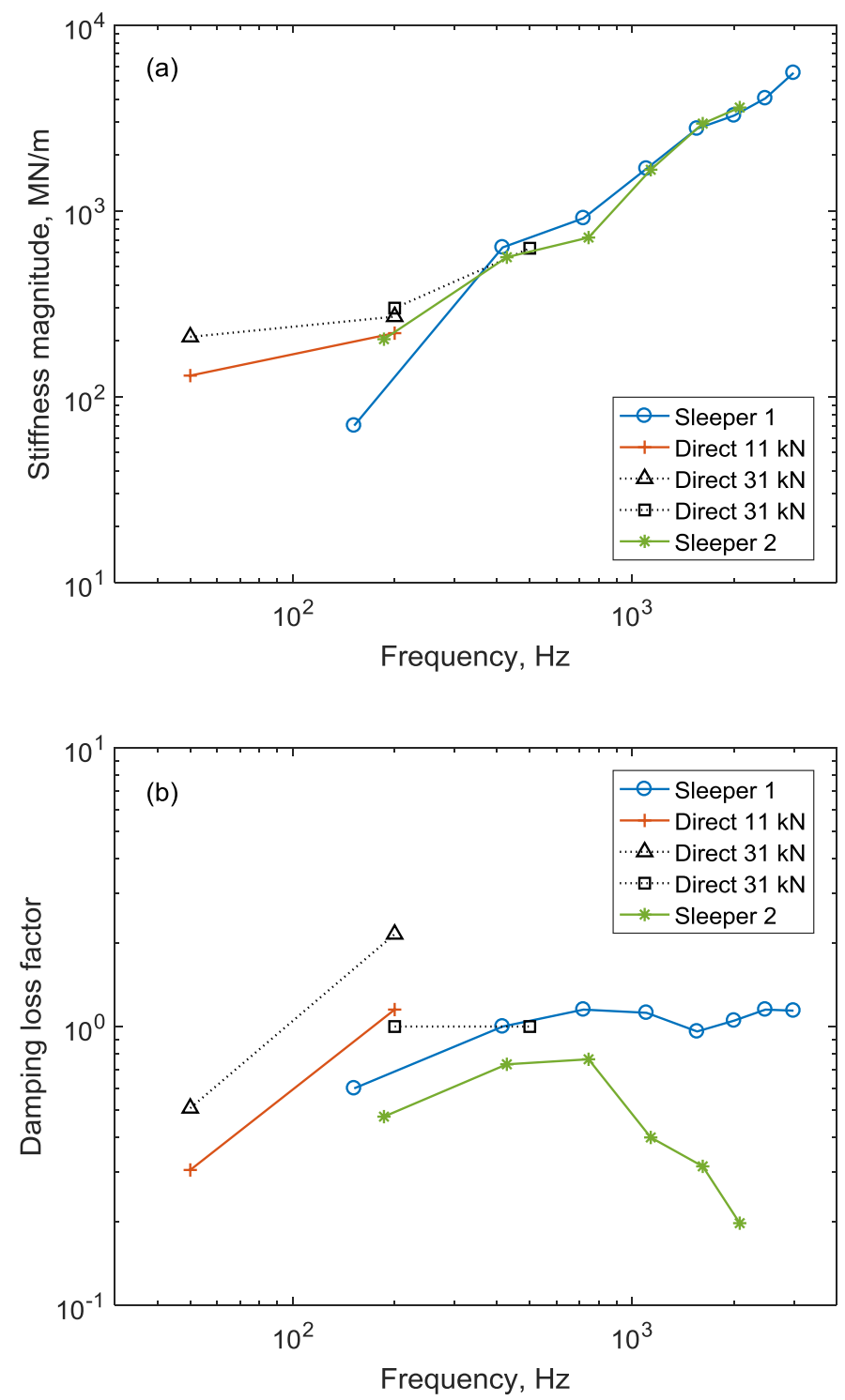

Figure 8. Summary of dynamic support stiffness results obtained from in situ measurements.

Results are shown as magnitude of dynamic stiffness and loss factor for one half sleeper.

The damping results can also be expressed as an equivalent viscous damping coefficient, given by $C=\eta K / \omega$. This is shown in Figure 9, based on the above results. Again, although the results under preload are higher than those without, the damping coefficient can be seen 
to be approximately independent of frequency, with values generally between 100 and $200 \mathrm{kNs} / \mathrm{m}$.

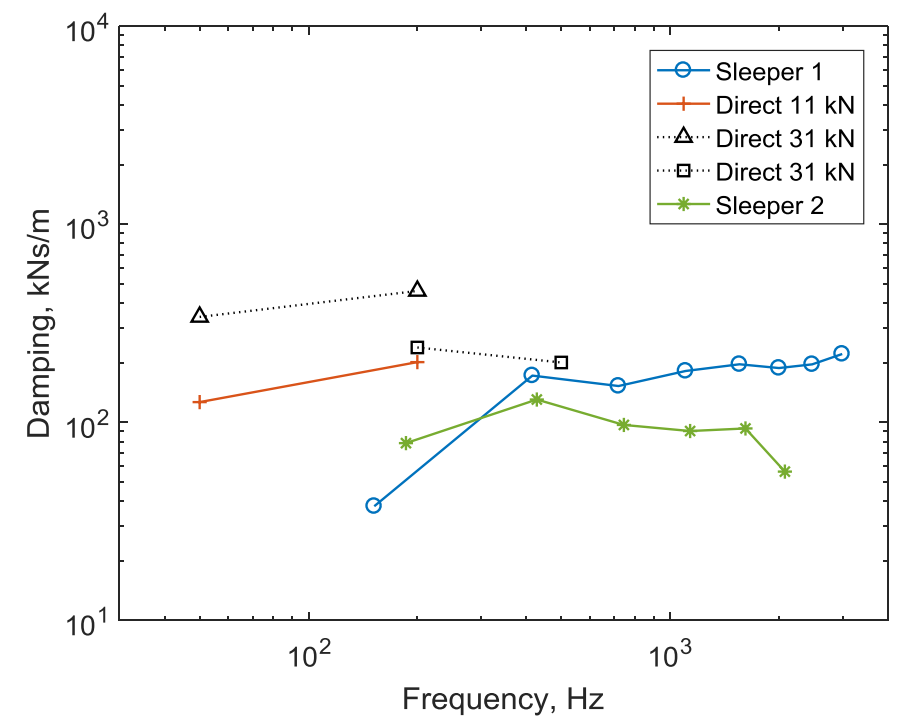

Figure 9. Summary of damping coefficient results obtained from in situ measurements.

Results are shown for one half sleeper.

\section{Finite element model of in situ dynamic support stiffness}

In order to reconcile the dynamic support stiffness results from Sections 4 and 5 with the ballast stiffness measurements from Sections 2 and 3, a finite element model of the ballast and ground has been established using COMSOL. A quarter domain of the ballast and ground is used, as shown in Figure 10. The boundaries at the symmetry planes have been set to be symmetric and a 'low-reflecting' boundary is used on the outer surface of the ground (the quarter hemisphere). Two different sets of parameters are used for both the ground and the ballast, as listed in Table 6. The radius of the ground region is $6.4 \mathrm{~m}$, which corresponds to one wavelength of shear waves at $47 \mathrm{~Hz}$ for the stiffer ground. The ballast has a width of 3.6 $\mathrm{m}$ at its base and $3.0 \mathrm{~m}$ at the top and its height is $0.4 \mathrm{~m}$. Both the ballast and the ground have been modelled using solid finite elements. For the excitation, a prescribed harmonic vertical displacement is applied to an area where the sleeper would be placed. The excitation area is marked in Figure 10(a). The applied force is determined by integrating the normal stress over this area and the dynamic stiffness is obtained from the ratio of this force to the applied displacement amplitude. The mesh is generated using a core region, with radius $3 \mathrm{~m}$, to obtain a good mesh resolution in the vicinity of the excitation. In total, 725,000 quadratic 
tetrahedral elements have been used; the maximum element size used for the ground is $0.25 \mathrm{~m}$.

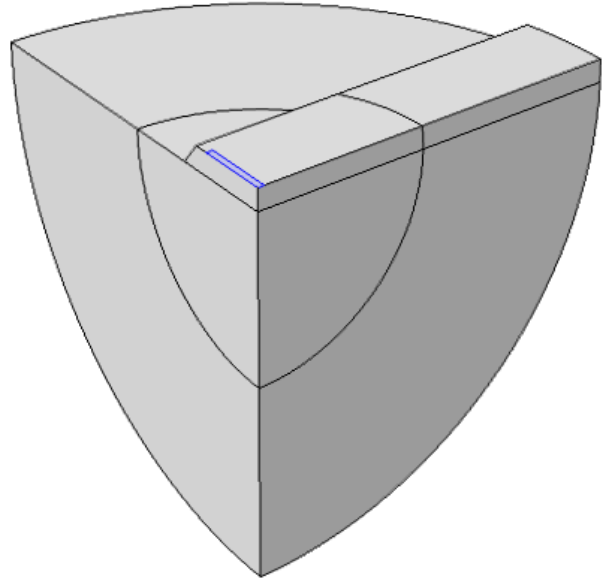

(a)

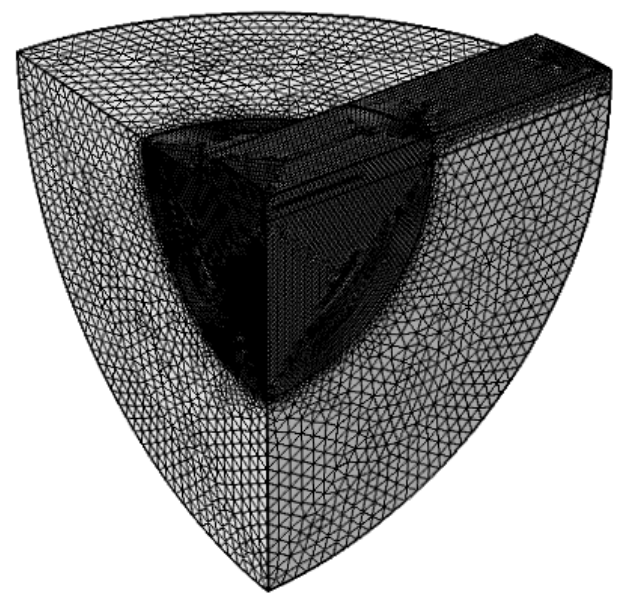

(b)

Figure 10. Finite element model of ground and ballast: (a) domain and (b) mesh.

Table 6 Properties used for ballast and ground in finite element model

\begin{tabular}{|l|l|l|l|l|l|}
\hline & $\begin{array}{l}\text { Young's } \\
\text { modulus, MPa }\end{array}$ & $\begin{array}{l}\text { Poisson's } \\
\text { ratio }\end{array}$ & $\begin{array}{l}\text { Density, } \\
\mathrm{kg} / \mathrm{m}^{3}\end{array}$ & $\begin{array}{l}\text { Damping } \\
\text { loss factor }\end{array}$ & $\begin{array}{l}\text { Shear wave } \\
\text { speed, } \mathrm{m} / \mathrm{s}\end{array}$ \\
\hline Ballast 1 & 214 & 0.2 & 1500 & 0.2 & 244 \\
\hline Ballast 2 & 428 & 0.2 & 1500 & 0.2 & 345 \\
\hline Stiffer ground & 428 & 0.3 & 1835 & 0.04 & 300 \\
\hline Softer ground & 107 & 0.3 & 1835 & 0.04 & 150 \\
\hline
\end{tabular}

Figure 11 shows the dynamic support stiffness (for half a sleeper) predicted from the numerical model for the stiffer ground. For both sets of ballast parameters, the predictions have similar trends in terms of both the magnitude and the phase. A similar trend is seen to the measured data presented in Figure 8. The predicted stiffness magnitude is similar to the measured one above $200 \mathrm{~Hz}$, where it increases in proportion to the frequency. A constant value of stiffness is found below about $100 \mathrm{~Hz}$, although this will be influenced by ground layering, not considered here. In the numerical results, the phase is close to $\pi / 2$ above 300 $\mathrm{Hz}$, which is similar to that of a viscous damper, whereas the measured values in Figure 8 tend to $\pi / 4$. These results from the FE model are consistent with the receptance of a halfspace excited over a certain area, which has been shown to be equivalent to a spring and a dashpot 
in parallel [46]. In such an ideal case the low frequency stiffness is proportional to the Young's modulus (when the dimensions of the excited area are small compared with the shear wavelength) whereas the damper coefficient is proportional to the square root of the shear modulus.
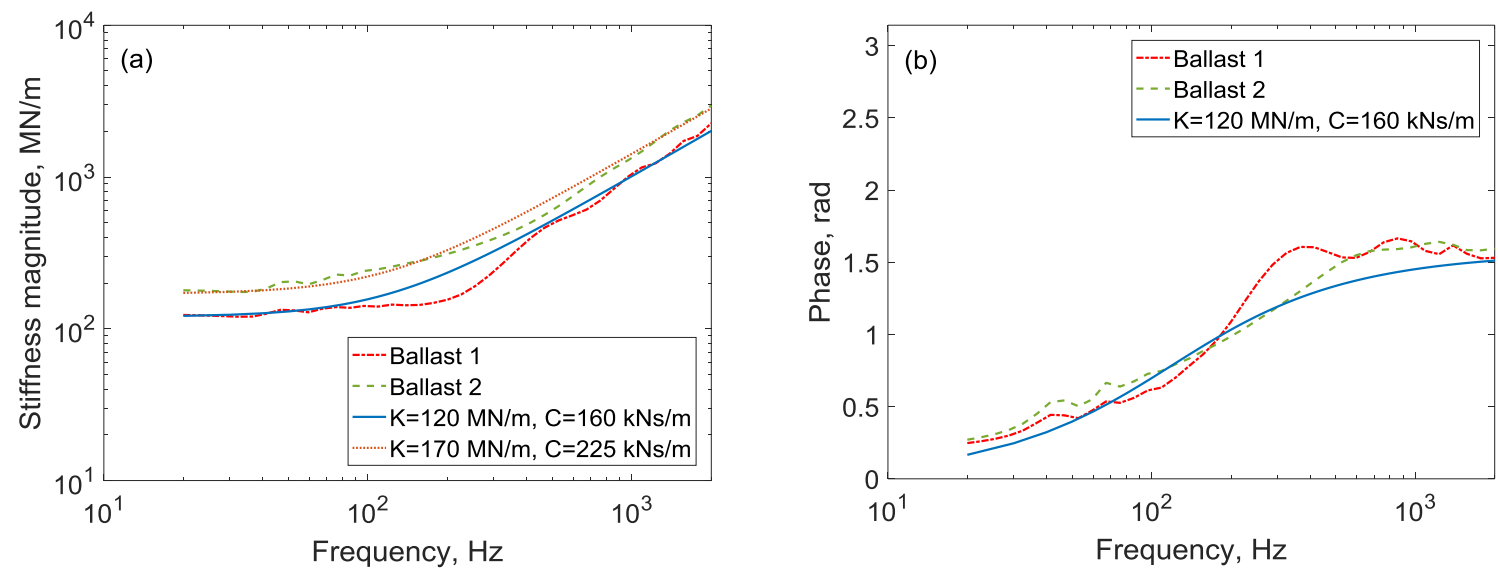

Figure 11. Dynamic support stiffness obtained from FE model for stiffer ground: (a) stiffness magnitude; (b) phase. Spring-damper approximation based on $K=120 \mathrm{MN} / \mathrm{m}$, $C=160 \mathrm{kNs} / \mathrm{m}$ and $K=170 \mathrm{MN} / \mathrm{m}, C=225 \mathrm{kNs} / \mathrm{m}$.

The asymptotic behaviour in Figure 11 is fitted by a spring and dashpot in parallel, using stiffness $K=120 \mathrm{MN} / \mathrm{m}$ and damping $C=160 \mathrm{kNs} / \mathrm{m}$ for ballast 1 , and $K=170 \mathrm{MN} / \mathrm{m}$, $C=225 \mathrm{kNs} / \mathrm{m}$ for ballast 2 . The phase is identical in both cases so it is only shown for the first case. The cross-over between stiffness and damping controlled behaviour, at which $\omega C=K$, is $120 \mathrm{~Hz}$ in both cases. The value of equivalent damper at high frequency can be seen to be proportional to the square root of the shear modulus of the ballast; at high frequency, the motion in the ballast will resemble that of a half-space of ballast material with deformation limited to a depth that is proportional to the Rayleigh wavelength; the underlying soil has no influence at high frequency.

The stiffness-like behaviour at low frequencies will also be affected by the stiffness of the underlying ground. Results are shown in Figure 12 for a softer ground, which has a Young's modulus that is one quarter of that of the stiffer ground. The corresponding low frequency stiffnesses of the combined system reduce by a factor of 2. Consequently, the cross-over between stiffness and damping controlled behaviour occurs at a lower frequency (around $60 \mathrm{~Hz}$ ). However, the damping-controlled region is mainly controlled by the ballast layer and 
so is not affected significantly by the change in ground properties, either in magnitude or phase and the same values of $C$ are used in the fitted curve as in Figure 11.
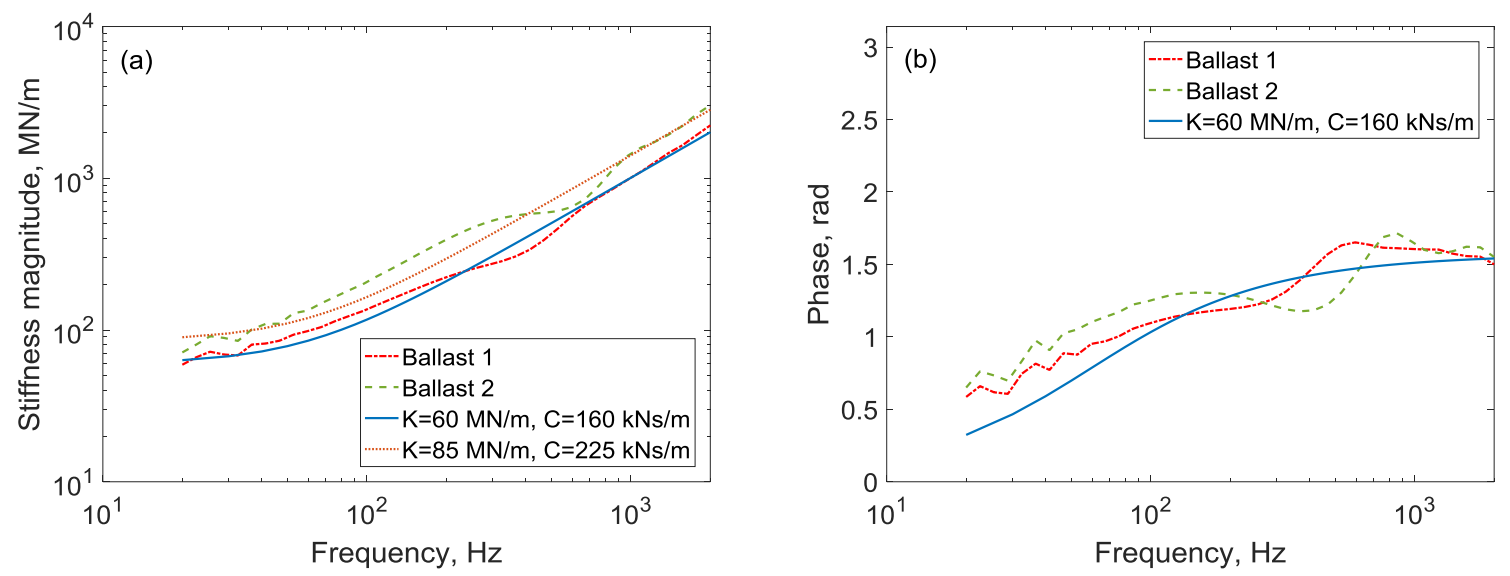

Figure 12. Dynamic support stiffness obtained from FE model for softer ground: (a) stiffness magnitude; (b) phase. Spring-damper approximation based on $K=60 \mathrm{MN} / \mathrm{m}$, $C=170 \mathrm{kNs} / \mathrm{m}$ and $K=85 \mathrm{MN} / \mathrm{m}, C=225 \mathrm{kNs} / \mathrm{m}$.

Additional results are shown in Figure 13 for a case consisting only of the ballast layer which is rigidly constrained at its base. The low frequency stiffness is higher than in Figure 11 and 12 as it is only determined by the ballast layer. There is a dip between 200 and $300 \mathrm{~Hz}$ caused by standing waves in the ballast layer. Above about $400 \mathrm{~Hz}$ the results are very similar to those seen in Figure 11 apart from some oscillation. This confirms that the underlying ground only influences the stiffness at low frequency. This effect can also be seen in [47].
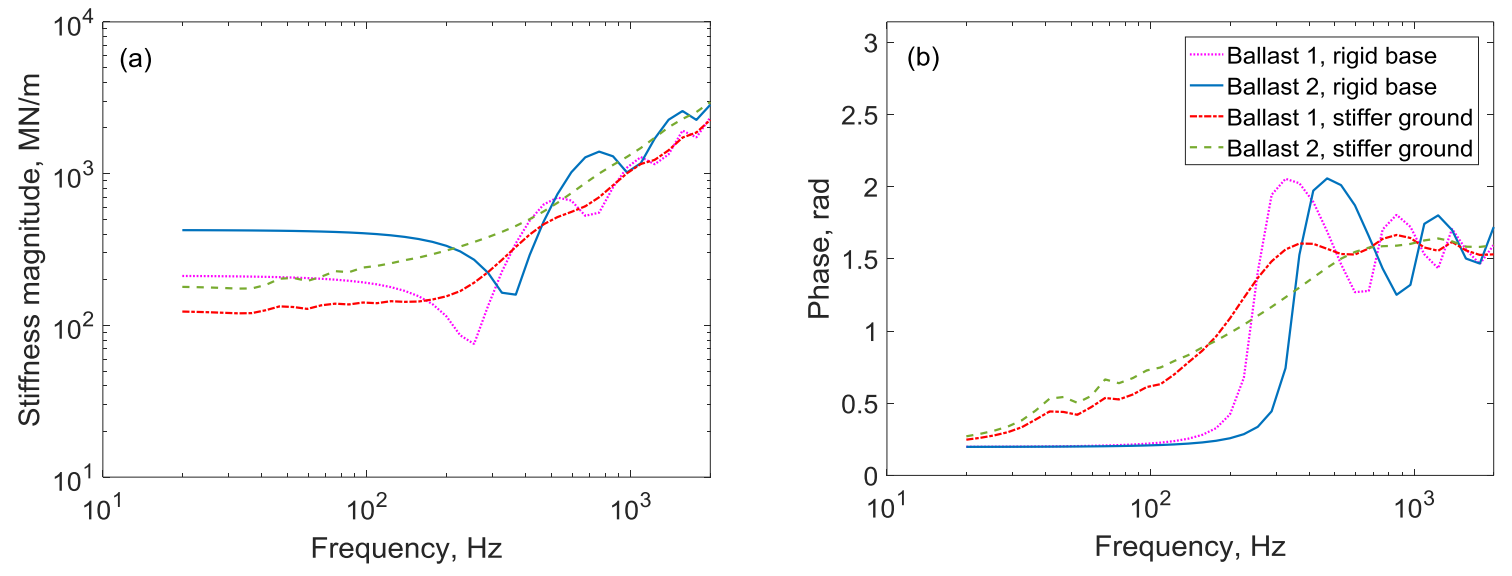

Figure 13. Predicted dynamic support stiffness of the ballast layer on a rigid foundation, compared with the stiffer ground: (a) magnitude; (b) phase. 


\section{Effect of support model on sleeper vibration}

The effect of the dynamic support stiffness on the vibration of the sleeper is important for rolling noise [37]. The measured results for the support stiffness of the sleeper (Figure 8) are currently used in the TWINS model [48]. They imply a frequency-dependent stiffness with a constant loss factor. On the other hand, the FE model in Section 6 gives results that correspond to a constant stiffness in parallel with a viscous damper. The magnitude of the dynamic stiffness is similar in each case but the phase is different $(\pi / 4$ for the constant loss factor and $\pi / 2$ for the viscous damping model). In this section, the response of a Timoshenko beam model for the sleeper [37] is compared for these two different support models. The parameters used for the sleeper are listed in Table 7.

Table 7. Parameters used to describe concrete sleeper.

\begin{tabular}{|l|l|}
\hline Young's modulus $\left(\mathrm{N} / \mathrm{m}^{2}\right)$ & $4.3 \times 10^{10}$ \\
\hline Poisson's ratio & 0.16 \\
\hline Sleeper damping loss factor & 0.01 \\
\hline Density $\left(\mathrm{kg} / \mathrm{m}^{3}\right)$ & 2570 \\
\hline Shear coefficient & 0.83 \\
\hline Length, m & 2.5 \\
\hline Excitation point, from one end $(\mathrm{m})$ & 0.5 \\
\hline Support stiffness (viscous damping model) & $120 \mathrm{MN} / \mathrm{m}^{2}$ \\
\hline Support damping (viscous damping model) & $120 \mathrm{kNs} / \mathrm{m}^{2}$ \\
\hline Support stiffness (hysteretic damping model) & $85 \mathrm{MN} / \mathrm{m}^{2}$ \\
\hline Support damping loss factor (hysteretic damping model) & 1.0 \\
\hline
\end{tabular}

Results are compared for three different support conditions. These are (i) a constant stiffness and viscous damping coefficient (consistent with the finite element results of Section 6); (ii) a frequency-dependent stiffness and constant loss factor (consistent with the measured results of Section 5); and (iii) a constant stiffness and loss factor. The values used are given in Table 7. For the frequency-dependent stiffness, a constant value is used below $100 \mathrm{~Hz}$ and above $100 \mathrm{~Hz}$ it is multiplied by $f / 100$, where $f$ is the frequency [37]. The magnitude and phase of the corresponding dynamic stiffnesses are shown in Figure 14. The magnitudes of the complex stiffness are equal in each case at low frequency; at high frequency the imaginary part is similar for cases (i) and (ii) although their phases differ. 

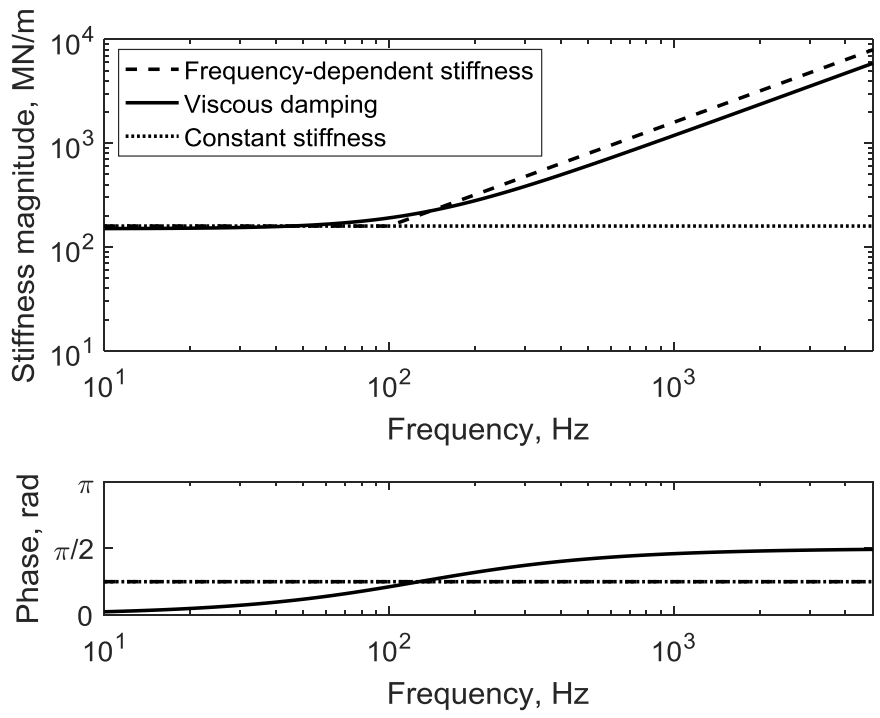

Figure 14. Assumed dynamic support stiffness used in the sleeper model.

Figure 15 shows the point mobility of the sleeper at the rail seat in each case. The model with constant stiffness and loss factor exhibits strong resonant behaviour at higher frequencies. However, for both the viscous damping model and the frequency-dependent stiffness model, these are strongly damped. These two models give very similar behaviour apart from a small shift in the resonance frequencies.

In the measured results in Section 5, a noticeable shift was found in the natural frequencies of the sleeper which implied the presence of a frequency-dependent support stiffness (Tables 4 and 5) whereas the increased modal damping implied a damping coefficient that is approximately independent of frequency (Figure 9). Of these two effects, the added damping is more important in determining the average response of the sleepers; the shift in natural frequency is not significant in terms of the overall response of the sleeper (and its noise radiation), especially if the results are converted to one-third octave bands. Thus, a model with a constant stiffness and viscous damping coefficient can be used as a reasonable approximation to determine the response of the sleeper in practical applications. 

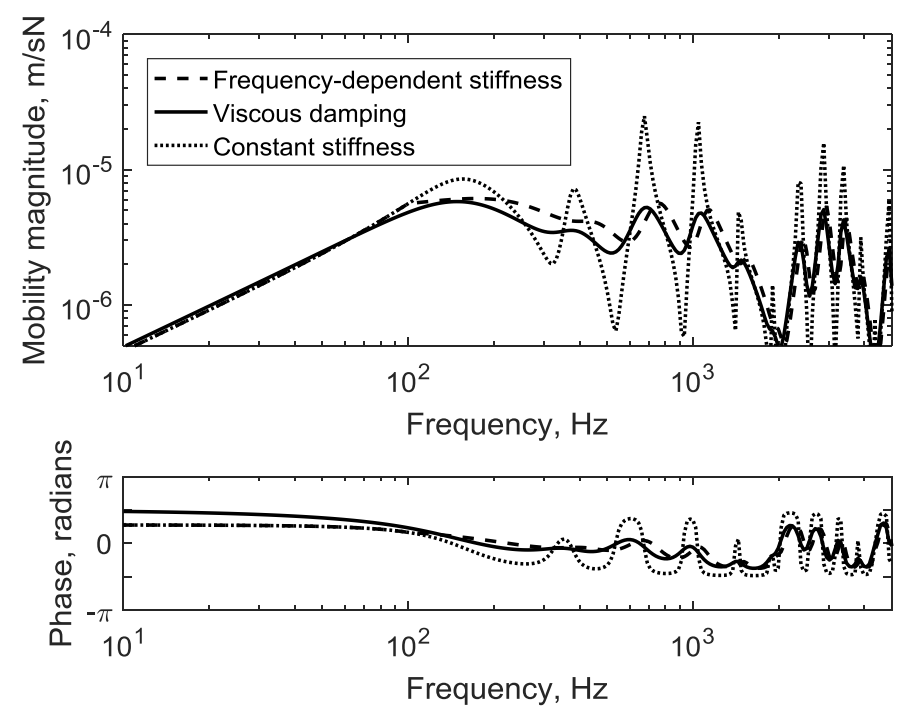

Figure 15. Effects of the ballast modelling on the point mobility of the sleeper based on dynamic stiffness from Figure 15.

\section{Conclusions}

The dynamic transfer stiffness of a layer of ballast has been measured using two different methods, one in the laboratory and the other in the field. The laboratory test rig is limited to a maximum frequency of about $600 \mathrm{~Hz}$, whereas the field measurement, which relies on identifying the wavespeed, gives results up to $2 \mathrm{kHz}$. These give broadly consistent results, with a stiffness per rail seat of a $300 \mathrm{~mm}$ thick ballast layer of approximately $300-500$ $\mathrm{MN} / \mathrm{m}$, increasing in proportion to the square root of the preload. The corresponding Young's modulus is between 200 and $700 \mathrm{MPa}$, depending on the preload. The damping loss factor is estimated to be between 0.1 and 0.3 by the two methods. The dynamic stiffness increases above about $300 \mathrm{~Hz}$ with a first peak due to standing wave effects occurring at about $700 \mathrm{~Hz}$ for a preload of $20 \mathrm{kN}$.

The dynamic support stiffness beneath the sleeper has been measured using a direct method for frequencies $50-500 \mathrm{~Hz}$. Mass compensation has to be applied to allow for the mass of the loading structure. At higher frequencies the modal response of a concrete sleeper is affected by the support stiffness and damping. The high damping makes the natural frequencies difficult to identify precisely, but nevertheless a clear shift in natural frequencies is seen which is associated with support stiffness rather than damping. The resulting stiffness 
is strongly frequency-dependent, increasing from about $100-200 \mathrm{MN} / \mathrm{m}$ at $100 \mathrm{~Hz}$ up to around $2000 \mathrm{MN} / \mathrm{m}$ at $1 \mathrm{kHz}$ (per rail seat). The support damping corresponds to a loss factor of around 1 for this frequency-dependent stiffness or a viscous damping coefficient of 100 $200 \mathrm{kNs} / \mathrm{m}$ per rail seat. This damping is due to the radiation of energy into the ground rather than internal losses in the ballast. The effect of preload in this case is smaller than for the ballast layer alone; the sleeper support stiffness increases roughly in proportion to $N^{1 / 3}$. There is no consistent increase in damping coefficient or damping loss factor with increasing preload. When large preloads are applied to the sleeper there is no longer a clear modal response which prevents identification of the dynamic stiffness at higher frequencies.

Comparison with a finite element model indicates that the underlying ground is responsible for the support stiffness at low frequencies. However, above about $500 \mathrm{~Hz}$ the support stiffness is independent of the ground and only affected by the ballast layer. Although the measured high frequency dynamic stiffness of the support has a phase of around $\pi / 4$, corresponding to a loss factor of 1 , the results of the FE model tend to a phase of $\pi / 2$, corresponding to a viscous damper. The sleeper vibration obtained using either of these dynamic stiffnesses is similar.

\section{Acknowledgement}

The work described here has been supported by the EPSRC under the programme grants EP/H044949/1, 'Railway Track for the $21^{\text {st }}$ Century (Track 21)' and EP/M025276/1, 'The science and analytical tools to design long life, low noise railway track systems (Track to the Future)'.

\section{References}

1. C. Esveld, Modern Railway Track, 2nd Ed. 2001, MRT Productions: Zaltbommel.

2. W. Powrie, L. Le Pen (eds). A guide to track stiffness. University of Southampton, 2016 (http://t2f.org.uk/wp-content/blogs.dir/sites/5/2016/10/A-Guide-to-Track-Stiffness_finalreviewR13_online-version.pdf)

3. P. Wang, L. Wang, R. Chen, J. Xu, J. Xu, M. Gao. Overview and outlook on railway track stiffness measurement. Journal of Modern Transportation 2016; 24 (2):89-102. 
4. L. Le Pen, D. Milne, D. Thompson, W. Powrie. Evaluating railway track support stiffness from trackside measurements in the absence of wheel load data. Can. Geotech. J. 53: 1156-1166 (2016).

5. P. Sharpe, C.R. Govan (2014). The use of falling weight deflectometer to assess suitability of routes for line speed increase. Proc 2nd International Conference on Railway Technology, Corsica. Paper 134, 1 - 16.

6. J.A. Priest, W. Powrie, Determination of dynamic track modulus from measurement of track velocity during train passage. J. Geotech. Geoenviron. Eng. 2009, 135, 1732-1740.

7. E. Berggren, A. Nissen, B. Paulsson, Track deflection and stiffness measurements from a track recording car, Proc. Inst. Mech. Eng. Part F J. Rail Rapid Transit 228 (6) (2014) 570-580.

8. M. Kohler 2002. Der Bettungsmodul für den Schotteroberbau von Meterspurbahnen. Doctoral Thesis, ETH Zurich

9. J.L. Eisenmann, L. Mattner: Auswirkungen der Oberbaukonstruktion auf die Schotterund Untergrundbeanspruchung. Eisenbahningenieur, 3/1984. (35): p. 99-107.

10. G. Leykauf, L. Mattner: Elastisches Verformungsverhalten des Eisenbahnoberbaus Eigenschaften und Anforderungen. Eisenbahningenieur, 3/1990. (41): p. 111-119.

11. K. Knothe, S.L. Grassie, Modeling of railway track and vehicle/track interaction at high frequencies, Vehicle System Dynamics 22, 209-262, 1993.

12. S.L. Grassie, R.W. Gregory, D. Harrison, K.L. Johnson, The dynamic response of railway track to high frequency vertical excitation. J. Mech. Engineering Science 24 (1982), $77-$ 90.

13. S.L. Grassie, S.J. Cox, The dynamic response of railway track with unsupported sleepers. Proc Instn Mech Engrs 199D (1985) 123-135.

14. B. Ripke, Anpassung der Modellparameter eines Gleismodells an gemessene Gleisrezeptanzen. TU Berlin, ILR Mitteilung 274 (1992).

15. C. Bancillon, H. Mahé, N. Vincent, Characterization of track receptances under a static load. Report VIBRATEC Nr 072-015 for D185 ERRI Committee 1992.

16. S.L. Grassie, S.J. Cox: "The dynamic response of railway track with flexible sleepers to high frequency vertical excitation", Proc. Instn Mech. Engrs Vol 198D No7 117-124, 1984.

17. G. de France, Railway track: effect of rail support stiffness on vibration and noise. MSc dissertation, ISVR, University of Southampton, 1998. 
18. N. Vincent, D.J. Thompson, Track dynamic behaviour at high frequencies. Part 2: experimental results and comparison with theory. Vehicle System Dynamics Suppl. 24, 100-114, 1995.

19. M. Oregui, Z. Li and R. Dollevoet, An investigation into the vertical dynamics of tracks with monoblock sleepers with a 3D finite-element model. Proc. Instn Mech. Engrs part F, J Rail Rapid Transit 230(3) 891-908, 2016.

20. J. Oscarsson, 2002. Simulation of train-track interaction with stochastic track properties. Vehicle System Dynamics, 37: 449-469.

21. A. Igeland, J. Oscarsson 1997 Modelling of railway track for computer simulation of dynamic train/track interaction. Proceedings of $15^{\text {th }}$ International Modal Analysis Conference, Tokyo, Japan, September 1997.

22. M. Germonpré, J.C.O. Nielsen, G. Degrande, G. Lombaert, Contributions of longitudinal track unevenness and track stiffness variation to railway induced vibration. Journal of Sound and Vibration 437 (2018) 292-307.

23. J.C.O. Nielsen, A. Igeland, Vertical dynamic interaction between train and track influence of wheel and track imperfections. Journal of Sound and Vibration 187, 825-839, 1995.

24. D.J. Thompson, N. Vincent, Track dynamic behaviour at high frequencies. Part 1: theoretical models and laboratory measurements. Vehicle System Dynamics Suppl. 24, 86-99, 1995.

25. D.J. Thompson, B. Hemsworth, N. Vincent. Experimental validation of the TWINS prediction program for rolling noise, Part 1: description of the model and method. Journal of Sound and Vibration, 193, 123-135, 1996.

26. X. Sheng, C.J.C. Jones, D.J. Thompson, A theoretical model for ground vibration from trains generated by vertical track irregularities. Journal of Sound and Vibration 272 (2004) 937-965.

27. W. M. Zhai, K. Y. Wang, and J. H. Lin. Modelling and experiment of railway ballast vibration. Journal of Sound and Vibration, 270, 673-683, 2004.

28. D. R. Ahlbeck, H. C. Meacham, R. H. Prause. The development of analytical models for railroad track dynamics. Railroad Track Mechanics \& Technology, Pergamon Press, Oxford, 1978.

29. J. A. Zakeri, S.A. Mosayebi. Study of ballast layer stiffness in railway tracks. Gradevinar 68, 311-318, 2016. 
30. L. Auersch. The excitation of ground vibration by rail traffic: theory of vehicle-track-soil interaction and measurements on high-speed lines. Journal of Sound and Vibration 284, 103-132, 2005.

31. L. Auersch. Dynamics of the railway track and the underlying soil: the boundary-element solution, theoretical results and their experimental verification, Vehicle System Dynamics 43, 671-695, 2005.

32. L. Hall. Simulations and analyses of train-induced ground vibrations; a comparative study of two- and three-dimensional calculations with actual measurements. PhD Dissertation. Department of Civil and Environmental Engineering, Royal Institute of Technology, Stockholm, Sweden; 2000.

33. H. Chebli, D. Clouteau, L. Schmitt. Dynamic response of high-speed ballasted railway tracks: 3D periodic model and in situ measurements. Soil Dyn Earthquake Eng 2008;28(2):118-31.

34. G. Saussine, C. Cholet, P.E. Gautier, F. Dubois, C. Bohatier, J.J. Moreau. Modelling ballast behaviour under dynamic loading. Part 1: A 2D polygonal discrete element method approach. Comput. Methods Appl. Mech. Engrg. 195 (2006) 2841-2859

35. J. Harkness, A. Zervos, L. Le Pen, S. Aingaran, W. Powrie (2016) Discrete element simulation of railway ballast: modelling cell pressure effects in triaxial tests. Granular Matter, 18 (65), 1-13.

36. P. Gardonio, M.J. Brennan, Mobility and impedance methods in structural dynamics, chapter 9 in F. Fahy and J. Walker (eds) Advanced applications of acoustics, noise and vibration, E\&FN Spon, London, 2004.

37. D. Thompson. Railway noise and vibration mechanisms, modelling and means of control. Elsevier, Oxford, 2008.

38. C.J.C. Jones, D.J. Thompson, M.G.R. Toward. The dynamic stiffness of the ballast layer in railway track. Structural Dynamics: Recent advances - Proceedings of the $7^{\text {th }}$ International Conference, 2000, Southampton, UK.

39. D. Herron, C.J.C. Jones, D. Thompson, D. Rhodes. Characterising the high-frequency dynamic stiffness of railway ballast. The $16^{\text {th }}$ International Congress on Sound and Vibration, Krakow, Poland, 2009.

40. D. Herron, Vibration of railway bridges in the audible frequency range. Doctoral thesis, University of Southampton, 2009 
41. ISO 10846-3 2002 Acoustics and vibration - Laboratory measurement of vibro-acoustic transfer properties of resilient elements - Part 3: Indirect method for determination of the dynamic stiffness of resilient supports for translator motion.

42. A. Aikawa, Dynamic characterisation of a ballast layer subject to traffic impact loads using three-dimensional sensing stones and a special sensing sleeper. Construction and Building Materials 92 (2015) 23-30.

43. G.R. McDowell, M.D. Bolton. Micro mechanics of elastic soil. Soils and Foundations 41, 147-152, 2001.

44. S. Oztoprak, M.D. Bolton. Stiffness of sands through a laboratory test database. Géotechnique 63, 54-70, 2013.

45. N. Frémion, J.P. Goudard and N. Vincent, Improvements of ballast and sleeper description in TWINS. Step 1: experimental characterization of ballast properties. Vibratec report 072.028a, July 1996.

46. K.L. Johnson, Contact Mechanics, Cambridge University Press, Cambridge, 1985.

47. X. Sheng, C.J.C. Jones, D.J. Thompson, A theoretical study of the influence of track parameters on train induced ground vibration. Journal of Sound and Vibration 272 (2004) 909-936.

48. D.J. Thompson, M.H.A. Janssens, F.G. de Beer, TWINS: Track-Wheel Interaction Noise Software, theoretical manual (version 3.0). TNO report HAG-RPT-990211, Delft, 1999. 